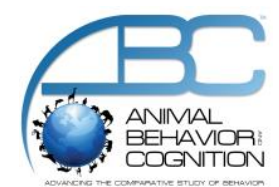

\title{
Social Context Predicts Vocalization Use in the Courtship Behaviors of Weddell Seals (Leptonychotes weddellii): A Case Study
}

\author{
Ludivine R. Russell ${ }^{1}$, Jesse E. Purdy ${ }^{2, *}$, \& Randall W. Davis ${ }^{1}$
}

\author{
${ }^{1}$ Texas A\&M University at Galveston \\ ${ }^{2}$ Southwestern University \\ *Corresponding author (Email: purdy@ southwestern.edu)
}

Citation - Russell, L. R., Purdy, J. E., \& Davis, R. W. (2016). Social context predicts vocalization use in the courtship behaviors of Weddell seals (Leptonychotes weddellii): A case study. Animal Behavior and Cognition, 3(2), 95-119. doi: 10.12966/abc.04.05.2016

\begin{abstract}
Despite previous research, no study has convincingly demonstrated what role if any vocalizations might play in the reproductive behavior of Weddell seals (Leptonychotes weddellii). To better understand that role, we created an artificial territory for an adult, male Weddell seal under the shore-fast ice in McMurdo Sound, Antarctica, and recorded its in situ vocalizations and non-vocal behaviors with an underwater video camera and hydrophone while alone, with another male, and with one or more females. Additionally, we simultaneously recorded the vocalizations and non-vocal behaviors from a female interacting with the male. Analysis of $86 \mathrm{hr}$ of video and audio recordings showed: 1) the male vocalized more than the female, 2) the male's vocal repertoire was larger than the females' repertoire, 3) vocalizations changed quantitatively and qualitatively with social context, and 4) patterns of vocalizations and non-vocal behaviors were detected with Theme, pattern recognition software from Noldus Information Technology. These results provided strong evidence that vocalizations played an important role during courtship, and together with the significant behavioral sequences, vocal and non-vocal, they provided insight into the function of their vocalizations including chirps, growls, jaw claps, knocks, mews, trills, and trills + knocks.
\end{abstract}

Keywords - Weddell seals, Leptonychotes weddellii, Vocalizations, Courtship, Resource defense polygyny, Malemale competition, Female-mate choice, Gender specific vocalizations, Social context

Weddell seals (Leptonychotes weddellii). (Order Carnivora, Family Phocidae) are large (body mass ca.400 kg) pinnipeds (i.e., seals, sea lions, walruses) that live beneath and on the shore-fast and pack ice surrounding Antarctica. Their mating system is Resource Defense Polygyny (RDP) (Freeman \& Herron, 2001; Harcourt, Kingston, Cameron, Waas, \& Hindell, 2007; Kooyman, 1981; Le Boeuf, 1991;) wherein males compete for resources that females need to mate successfully and females choose males whose genes provide their offspring their best chance to survive to reproduce (Emlen \& Oring, 1977). The primary resource for which Weddell seal males compete are territories that can provide females with ready access to one of the sparsely distributed breathing holes in the shore-fast ice from which she can stage exploratory and foraging dives (Kooyman, 1981). RDP is common among mammalian species including seals where males cannot defend a harem due to environmental constraints or physical limitations (Boness, 1991; Boness, Bowen, \& Francis, 1993; Emlen \& Oring, 1977).

Weddell seals are highly vocal with a large repertoire of calls or vocalizations that has been 
hypothesized to play an important role in reproductive behavior (Pahl, 1995; Ray \& Schevill, 1967; Thomas \& Kuechle, 1982; Thomas, Puddicombe, George, \& Lewis, 1988; Wilson, 1907), although the functional roles of most calls remain unknown. Vocalizations are important for social interactions for many marine mammals because sound travels 4.6-fold faster in water, and the attenuation coefficient is one-tenth of that in air. These characteristics of sound enable seals to detect one another over distances exceeding one kilometer. Whereas much of the information males and females need to mate successfully could be obtained visually, visibility underwater is easily compromised by environmental conditions including reduced light from snow cover, plankton blooms, distance, and the location of a male's territory. Auditory signals are more reliable and carry over longer distances than visual ones giving females an opportunity to hear and possibly compare males from several different territories simultaneously. Vocalization rate, repertoire size, and characteristics of vocalizations including amplitude, duration, frequency range, and the addition of pre- and or post-vocalizations to certain calls could all serve as indices of male quality. Given the highly vocal nature of the Weddell seal and the advantages of auditory cues over visual ones males could increase their reproductive success by advertising with auditory signals and females could increase their fitness from the ability to assess a male's quality. All aquatically mating pinnipeds that have been studied are highly vocal (Wartzok \& Ketten, 1999), and in at least one species, the bearded seal (Erignathus barbatus), vocalizations have been shown to play an important role in reproduction (Van Parijs, Lydersen, \& Kovacs, 2003, 2004).

Previous research on Weddell seals provided circumstantial evidence that vocalizations played a role in reproductive behavior. This evidence included: 1) certain vocalizations appeared to be gender specific (Oetelaar, Terhune, \& Burton, 2003; Thomas \& Kuechle, 1982), 2) males vocalized more and appeared to possess a larger vocal repertoire than females (Thomas \& Kuechle, 1982), 3) vocalizations differed between geographic locations (Collins \& Terhune, 2006; Pahl, 1995; Pahl, Terhune, \& Burton, 1997; Thomas et al., 1988; Thomas \& Stirling, 1983), and 4) during the reproductive season, males lengthened certain calls when they were overlapped by those of a conspecific (Terhune, Grandmaitre, Burton, \& Green, 1994). Points 3 and 4 raised the possibility that individual differences existed among seals especially males. Individual differences would be necessary, but not sufficient, to support the hypothesis that vocalizations contained information regarding the fitness of the vocalizing seal.

Additional support has come from in situ playback experiments (Thomas, Zinnel, \& Ferm, 1983; Watkins \& Schevill, 1968) and from investigations that assessed the relative proportion of vocalizations during and after the reproductive season (Green \& Burton, 1988; Rouget, Terhune, \& Burton, 2007; Thomas, Ferm, \& Kuechle, 1987, 1988). However, both lines of evidence were of limited value. Findings from playback experiments were inconclusive because researchers were unable to link played back vocalizations with those of the responding seal(s) (Thomas et al., 1983; Watkins \& Schevill, 1968). Consequently, Thomas et al. (1983) concluded that playback experiments might not be the best approach with the highly vocal Weddell seal. With respect to the rate and proportion of certain vocalizations, no consistent patterns have been observed. Whereas some investigators observed more vocalizations during the breeding season than at other times of the year (Green \& Burton, 1988; Thomas et al., 1987, 1988) others found equal rates when only austral night vocalizations were compared (Rouget et al., 2007). To our knowledge only one study recorded differential use of specific calls during the breeding season and other times, however no consistent trends were observed for the three identified vocalizations (Pahl et al., 1996).

In the current study, we recorded the in situ behavior and vocalizations of male and female Weddell seals that utilized an enclosed artificial ice hole located at one end of our remote ice camp and accessible via a trapdoor. Although two or three seals could share the hole to breathe and rest between dives, the size and configuration of the facility precluded seals from hauling out. Recordings from an underwater video camera provided a broad view of the hole and the surrounding under ice environment. A hydrophone and amplifier linked to the video recorder provided a permanent record of the vocalizations and non-vocal behaviors of seals interacting in and around the artificial hole. This design enabled us to test more rigorously the main hypothesis that the vocalizations of Weddell seals play an important role in their reproductive behavior. The following alternative hypotheses were tested. If these hypotheses were 
confirmed the results would provide compelling evidence that the vocalizations of male and female Weddell seals emitted during the reproductive season comprised a complex communication system that benefitted both the sender and the recipient.

H1. The repertoire of vocalizations emitted by a male Weddell seal defending a territory will exceed that of a female residing in the male's territory. Further, both male and female seals will vocalize more when other seals are present than when either is alone. Finally, over the course of the reproductive season the male territory holder will vocalize more than a female residing in his territory.

Rationale. The predictions in $\mathrm{H} 1$ derived from the assumption that RDP defines the mating strategy of the Weddell seal (Freeman \& Herron, 2001; Harcourt et al., 2007; Kooyman, 1981; Le Boeuf, 1991; Thomas \& Stirling, 1983). To attract a female, a male should advertise that he is defending and maintaining a territory that has the resources she needs to mate successfully, that the female will be given free access to his territory, and that he is big, strong, and aggressive, and has the stamina to keep his territory throughout the mating season. In addition, the territory male should communicate to potential male intruders that he will aggressively and physically keep them from entering his territory. Females on the other hand do not need to advertise their quality because the male will mate with any receptive female in his territory (Emlen \& Oring, 1977). However, to avoid potential injury from the highly aggressive territory holder if sex is misidentified, the female should broadcast her sex, her presence, and her location. As a result of the need to communicate more and different messages to males and females entering his territory, the male's vocal repertoire should exceed that of a female resident and he should vocalize more than the female during the breeding season. Lastly, because the male territory holder and the female residents have information to communicate, both sexes should be more vocal when other seals are about than when they are alone.

H2. The vocalizations of the male territory holder and the females residing therein will differ according to social context (male alone, female alone, male/male, female/female, and male/female).

Rationale. Van Parijs et al. (2003, 2004) observed that the vocalizations from male bearded seals holding a territory during the reproductive season differed from those emitted by non-territory holders. Specifically, Van Parijs et al. showed that the frequency range was greater and call duration was longer for trills produced by male territory holders compared to non-territory holders. In addition, male territory holders had greater reproductive success than males that were too small, too young, or too inexperienced to hold a territory. Although these species are found at separate ends of the earth, bearded seals and Weddell seals reside on the shore-fast or pack ice, both species are highly vocal during the reproductive season, and both species are thought to copulate in water. These similarities add additional support to the predictions of $\mathrm{H} 1$ and to the possibility that the vocalizations of male Weddell seals holding a territory will differ depending on the sex of the seal entering or present in his territory. Given the male's need to send different messages to males and females, social context should affect either the rates or the types of vocalizations that territory holders send.

H3. Patterns of vocalizations, non-vocal behaviors, and combinations of vocalizations and nonvocal behaviors will be discovered. These behavioral sequences will be ritualized and their use will vary with social context.

Rationale. The existence of behavioral sequences of vocalizations, non-vocal behaviors, and combinations of vocalizations and non-vocal behaviors are becoming relatively common among mammalian species. For example, vervet monkeys emit different alarm vocalizations depending upon the type of predator detected and in turn these alarm calls evoke different and appropriate antipredatory behaviors (Cheney \& Seyfarth, 1980; Seyfarth \& Cheney, 1986; Struhsaker, 1967). Similar systems have also been observed in California ground squirrels interacting with birds of prey, coyotes, and rattlesnakes (Owings \& Coss, 1977). Although the behavioral system underlying mating behavior in Weddell seals differs from the defensive systems considered above, communications between two males, two or more females, and male and female dyads during the breeding season are no less important to the survival of the species. If the male's vocalizations communicate his fitness and genetic quality as well as his ability and stamina to defend his territory throughout the mating season then these messages must be clear, difficult to ignore, and repetitive. Therefore, one would expect that attention getting behavioral sequences 
of vocal and non-vocal behaviors will be discovered. Further these patterns should be ritualized (Rogers $\&$ Kaplan, 2002). To meet the requirements for a ritualized vocal display, the message should have a limited number of attention-getting components that are frequently repeated (Bradbury \& Vehrencamp, 1998; Turnbull \& Terhune, 1993) of stable duration and rhythm and that stand out from a noisy background reducing the chances of confusing the message or missing the signal entirely. In addition, these displays should allow for individual recognition (Moors \& Terhune, 2004) and these patterns should vary depending on social context and consequently they should provide insight into the function of specific vocalizations.

\section{Method}

\section{Study Site and Animals}

Data were collected in McMurdo Sound (77.693S, 166.306E), Antarctica during the austral spring between 25 October and 5 December, 2002. The study was conducted in parallel with an investigation of the hunting behavior and foraging ecology of Weddell seals (Davis, Fuiman, Williams, Horning, \& Hagey, 2003). A rectangular hole $(1.5 \times 2.75 \mathrm{~m})$ was cut into the ice $1.2 \mathrm{~km}$ from a Weddell seal rookery at Tent Island. A second hole, approximately $2 \mathrm{~m}$ from the larger seal hole was drilled for the purpose of deploying oceanographic equipment that measured light levels, current direction and speed, water temperature, and kept a record of time and depth. This device was suspended $50 \mathrm{~m}$ below the ice surface. In addition, the underwater camera and the hydrophone and associated equipment used to record seal behavior was suspended from this hole. A Jamesway (Quonset hut design) was constructed over the seal and oceanographic equipment holes to keep them from freezing and to provide laboratory and living quarters for the research team. Shortly after the artificial hole was drilled, two Weddell seals were observed breathing and resting in the hole. One of these seals, a male here after referred to as M1 (Pink tag, 841), established the holes in the ice and the surrounding area as his territory and over a six week period we observed him defend it and use it to recruit females. Observations of M1 and the other seals that were introduced to his territory or that arrived independently were made until deteriorating ice conditions forced us to end the study and remove our camp.

M1 the dominant male and territory holder served as the focal male and spent the majority of his time under the ice around his territory. Occasionally we found him hauled out on the ice near a second, natural hole about $150 \mathrm{~m}$ from the research camp. This hole was maintained by M1, but was not as large or as reliable as the artificial hole. Importantly, this hole allowed M1 to haul out on the ice where he could rest and possibly recover from wounds inflicted during encounters with male intruders (Williams, 2003). M1 was the only male we observed hauled out at this location. During this six-week study, four females, referred to as F1 (yellow tag, 1346), F2 (yellow tag, 1575), F3 (untagged but identified by size, fur color and pattern, and behavior), and F4 (tag, 4051, tag color not recorded) utilized M1's territory and associated hole as a base for resting and breathing between foraging and exploratory dives. Observations of F1 began 17 November. F2 and F3 first appeared in the hole on 25 November. F4 was observed on the last day of our study and her data were not included. None of the females had pups. F1 was present the longest and she served as the focal female. In addition to these free-ranging females we also introduced three males and seven females into M1's territory. The females were outfitted with biotelemetry gear including an underwater camera and audio recording equipment to learn more about their foraging and diving habits. Male seals were caught and released into M1's territory following their participation in a cross sectional study that examined changes in muscle mass over the lifespan of a Weddell seal. Most of the captured seals were hauled out on the ice along Tent Island, or the southwestern shore of Ross Island. These seals were captured and then transported to the lab where they were weighed and sedated before any experimental procedures were begun. All captured animals were held for $18 \mathrm{hr}$ prior to release to ensure they were fully recovered from the sedation. All captured seals were released through a trapdoor cut into the floor covering the artificial hole. The behaviors of the 'accessorized' females did not differ statistically from their free-ranging counterparts and hence their data were combined. 
Audiovisual recording began with the release of the first captured female for the purpose of ensuring that the biotelemetry equipment was properly affixed to the animal, was functioning, and was not affecting its behavior. We recorded the release of all captured animals up to $2 \mathrm{hr}$ post release. If a captured seal stayed in M1's territory longer than $2 \mathrm{hr}$ we recorded their behavior for an additional $2 \mathrm{hr}$ or until the captured seal left M1's territory. Recorded observations of the four free-ranging female seals began when we first observed F1 using the hole to stage foraging and exploratory dives. The free-ranging seals were recorded in two-hour blocks or until there had been no seals in M1's territory for $30 \mathrm{~min}$. The two-hour recordings were taken at various times throughout a $24 \mathrm{hr}$ period and were typically started when one of the females or M1 were observed breathing in the hole. The only exceptions to these recording periods occurred when the experimenters were not available to start a recording.

\section{Video and Audio Recordings}

Vocalizations were recorded with a hydrophone (TC 4032, frequency response: $5 \mathrm{~Hz}-120 \mathrm{kHz}$; Teledyne Reson Inc., Goleta, CA) that was suspended to a depth of $8 \mathrm{~m}$ from the hydrographic hole. The hydrophone was connected to an audio amplifier (Reson EC 6070), an MP3 player-recorder (Creative Nomad Jukebox, sampling rate: $44 \mathrm{kHz}$; Creative Technology, Ltd. Singapore), and a Sony videocassette recorder. Raven Pro 1.4: Bioacoustics Research Program (Krein \& Clark, 2011) was used to analyze and classify sample vocalizations from the focal male and female. Video recordings were obtained from an underwater camera (Pisces Design, San Diego, CA) that faced upwards and was centered below the oceanographic hole at a depth of $15 \mathrm{~m}$. This depth provided a view of the seal deployment hole and the surrounding area out to $6 \mathrm{~m}$ from all sides of the rectangular hole. A second camera was situated above the seal hole at a height of $2 \mathrm{~m}$. The hydrophone and underwater camera were suspended from the oceanographic hole to reduce the chances of damage when seals were interacting below the hole. On occasion a seal would bump into the hydrophone causing a single loud thump that was easily discriminated from a vocalizing seal. In the samples we analyzed, no seal ever struck the suspended camera or its electrical line. Overall the audiovisual equipment did not appear to disrupt the natural behavior of the seals.

A total of $102 \mathrm{hr}$ of recordings (51 two-hour recordings) were made over 26 different days. However, due to weather related equipment failure only $92 \mathrm{hr}$ had both video and audio recordings. During one 2-hr recording strong currents and a tide reversal caused the camera to move well off center making behavioral observations and individual identification difficult to impossible. Additionally, a problem was encountered for a total of four hours while we were encoding the video samples into MPEG2 files. Therefore, we analyzed $86 \mathrm{hr}$ of recordings: $38 \mathrm{hr}$ recorded by the underwater camera only, and $48 \mathrm{hr}$ simultaneously recorded by the underwater camera $(24 \mathrm{hr})$ and the above ice camera $(24 \mathrm{hr})$.

A Canopus MPEG encoder controlled by Canopus MediaCruise software converted the VHS tapes to MPEG2 files for the video analysis (Canopus Co. Ltd. Kobe, Japan). The Observer Video-Pro 5.0 (Noldus Information Technology Wageningen, Netherlands) provided the means to score vocalizations and non-vocal behaviors including: 1) the time when a seal vocalized or exhibited a behavior, 2) the location of the seal (e.g., on screen, outside viewing area, in the hole), 3) the identities of the seals, 4) the types of vocalizations produced in M1's territory (i.e., very loud vocalizations), 5) the number of vocalizations in a series (e.g., chirps, jaw claps, or knocks), 6) the types of non-vocal behaviors exhibited by the individual seals, and 7) the direction of swimming (e.g., toward or away from the hole, toward or away from another seal).

Seals were identified in the video based on several criteria. First, trills were male specific vocalizations (Thomas \& Kuechle, 1982; Thomas et al., 1983). Thus, when a loud trill was heard we knew that a male had emitted it and that the male was close to the hydrophone. We also knew that M1 was the territory holder and that he actively repelled other males from his territory. As long as we had not released a male into M1's territory, we could be confident that any loud trill we recorded had been produced by M1. Further once we learned that a long and loud trill was followed shortly and reliably by M1 arriving at the hole (89 recorded instances), when we heard a loud trill we were confident that M1 had 
produced it. Second, when a seal surfaced in the ice hole, we checked its flipper tag and recorded its identity along with the time. Third, with practice we could identify seals based on their appearance, behavior, and to an extent their vocalizations. For the latter we used Raven Pro 1.4 to compare the fundamental frequencies of the vocalization with previous vocalizations from a known seal or we could compare the fundamental frequencies of the same vocalization to determine whether the vocalizer was male or female (see Figures 1.1 and 1.2 for differences between M1's chirps and F1's chirps, and Figures $1.8,1.9,1.10,1.12$ for examples of M1's trills).

\section{Classification of Vocalizations and Non-vocal Behaviors}

Several classification methods for Weddell seal vocalizations exist (Pahl et al., 1997; Terhune, Burton, \& Green, 1994; Thomas \& Kuechle, 1982). Thomas and Kuechle's (1982) system which was based on frequency range, duration, repetition rate, number of elements per series, presence of auxiliary sounds and/or harmonics, and contour remains the most common method of analysis. Following this system Thomas and Kuechle identified 12 different calls with further delineation within certain calls. All told, 34 different vocalizations were established. Given the widespread use of this classification method we chose to follow it. However, following Thomas et al. (1987), we chose not to subdivide vocal categories. For example, whereas Thomas and Kuechle (1982) documented 11 different types of trills, we consolidated all trill types into one category. There was one exception: we distinguished between trills and trills + knocks. This distinction was made because M1 appeared to use these vocalizations differentially depending on social context. In addition, we grouped jaw claps with vocalizations. Jaw claps are produced when the seal opens its jaws wide and then brings them together rapidly and with force repeatedly. Though not strictly a vocalization its placement as one of eight vocal categories allowed us to see how social contexts affected their use. Table 1 lists the call categories we observed, the total number of times each call was recorded, the call's corresponding nomenclature from Thomas and Kuechle (1982) and a definition of the vocal category. A small percentage $(0.2 \%)$ of the calls could not be categorized, and were designated "Unknown." Sample sonograms of calls emitted by M1 and one or more females while they were alone, with another male, or with another female can be seen in Figure 1. The accompanying figure captions point out the relevant behaviors at the time the vocalization was heard.

Non-vocal behaviors included arriving and leaving the breathing hole, biting, swim toward the hole, swim away from the hole, swim toward a seal, and swim away from a seal, rest in the breathing hole, and rest beneath the hole. These behaviors were not mutually exclusive and consequently were grouped into two main categories: event and state behaviors. This system allowed behaviors to be exclusive within each category. Event behaviors "arrive," "leave," and "bite" were less than 2 s in duration and were always scored, even if a state behavior was concurrently occurring. State behaviors (all swimming and resting behaviors) had durations greater than $2 \mathrm{~s}$. They were scored when the behavior was initiated and every time there was a change. The time at which the state behavior ended was also noted. A distinction was made between "arriving" and "leaving" and "swim toward the hole" and "swim away from the hole." To be scored "arriving" or "leaving" the seal had to be rapidly swimming into the hole or out of the hole and following a straight path. When an animal arrived at the hole, it always breathed. To be scored "swim toward the hole" and "swim away from the hole" the seal had to be swimming slowly, producing a meandering path. Resting behaviors were scored whenever a seal stopped swimming for a period of $2 \mathrm{~s}$ or more. Resting typically occurred while the animal breathed at the surface or as it waited to breathe just beneath the hole.

\section{Assessing Observer Reliability}

To validate the video analysis, $10 \mathrm{hr}$ of video recordings for M1 were randomly selected and reanalyzed by a second observer. Overall, 1,975 vocalizations and behaviors were scored with $87 \%$ $(1,718)$ agreement. Because the percentage agreement statistic can potentially misrepresent inter-observer reliability (Kaufman \& Rosenthal, 2009), we also estimated Cohen's k-statistic (Cohen, 1960). However, 
one of the major assumptions of the k-statistic is that the behaviors are independent (i.e., the presence of the initial behavior does not change the probability of the following behavior). Given that behavioral independence was greater when M1 encountered a male than when he encountered a female, we computed the k-statistic during a two-hour recording when M1 encountered another male. Of 146 observations, there were 129 agreements producing a k-statistic of 0.86 . The high and consistent percentages of agreement coupled with the high k-statistic confirmed the reliability of the data.

\section{Data Analyses}

To determine whether vocalizations varied with changes in social context, we divided the audiovisual data into 15-min intervals and sorted them using Observer Video-Pro 5.0. It was not possible to obtain records of F1 alone. Even if M1 was not visibly in his territory, when F1 arrived at the hole, M1 quickly returned eliminating any chance of recording her alone for $15 \mathrm{~min}$. Consequently, data from eight social context categories were analyzed (Table 2). Sample sizes for each social context category ranged from a high of 133 for those periods when M1 and F1 were interacting to 9 the number of samples for "M1 Alone" and "M1 with three females." To equalize the large differences in sample size across social context categories, we analyzed the nine samples from the conditions "M1 Alone" and "M1 with three females" and then randomly selected nine samples from each of the remaining social contexts. Within each sample, we computed the means and confidence intervals for all vocalization types and non-vocal behaviors produced by M1 and F1. We chose the lowest common sample size to ensure a conservative analysis and to increase our effect sizes with a view toward increasing our confidence that the significant effects we discovered were real.

Normality was assessed using the Shapiro-Wilk test for degrees of freedom less than or equal to 50 and the Kolmogorov-Smirnov test when degrees of freedom exceeded 50. In most cases, the data were not normally distributed. Consequently, nonparametric statistical tests were used. Chi-Square Tests of Maximum Likelihood (Brown \& Downhower, 1988) determined whether M1 and F1 distributed their vocalizations differently depending on social context. If the overall Chi-Square test was significant we then tested the vocal categories separately to determine which vocalizations were affected by changing social contexts. To determine the direction of differences in vocalization use over the five social context categories for M1 and over the three social contexts for F1, Kruskal-Wallis tests were conducted. MannWhitney U tests provided post-hoc comparisons where needed. The False Discovery Rate procedure controlled for changing alpha levels (Curran-Everett, 2000). Accordingly, for all post-hoc multiple comparisons, the largest mean difference was tested against $p<0.017$ and the smallest difference was tested against $p<0.05$ (Curran-Everett, 2000). Effect sizes (Cohen's d-statistic for two mean comparisons, Cohen, 1988) were computed for all significant two-group comparisons. Although violations of normality and/or homogeneity of error variance can adversely affect estimates of effect size (Aberson, 2010), often the outcome is to reduce the actual effect size. Based on this likelihood, our estimates of effect size were thought to be conservative and were included in the analysis.

We used Theme, a pattern recognition software package (PatternVision Ltd., Reykjavik, Iceland, Noldus Information Technology, Inc.), to detect the existence of behavioral sequences produced by M1 and the seals with which he interacted. Theme detected patterns of behaviors that were linked by time (Tpatterns). In these tests behavioral sequences were randomly generated until a particular sequence was produced a required number of times. The minimum number of times a pattern had to occur within a sample was set to 5, and the maximum accepted probability of any pattern to occur by chance alone was set to 0.05 . Vocalizations and non-vocal behaviors were examined separately and in combination to determine whether certain behavioral sequences were being repeated more often than expected by chance. If such patterns were discovered and met the criteria for ritualized behavior they would provide support for Hypothesis 3 and when combined with social context and the identity of the interacting seals these sequential patterns could provide insight into the function of certain vocalizations. 
Table 1

Total Number of 15-min Samples for Each Social Context

\begin{tabular}{lc}
\hline Social Context & Total 15 min Samples \\
\hline M1 Alone & 9 \\
M1 + Male & 15 \\
M1 + Female & 133 \\
M1 + Females & 59 \\
M1 + 3 Females & 9 \\
F1 + M1 & 75 \\
F1 + M1 + Female & 59 \\
F1 + M1+2 Females & 9 \\
\hline
\end{tabular}

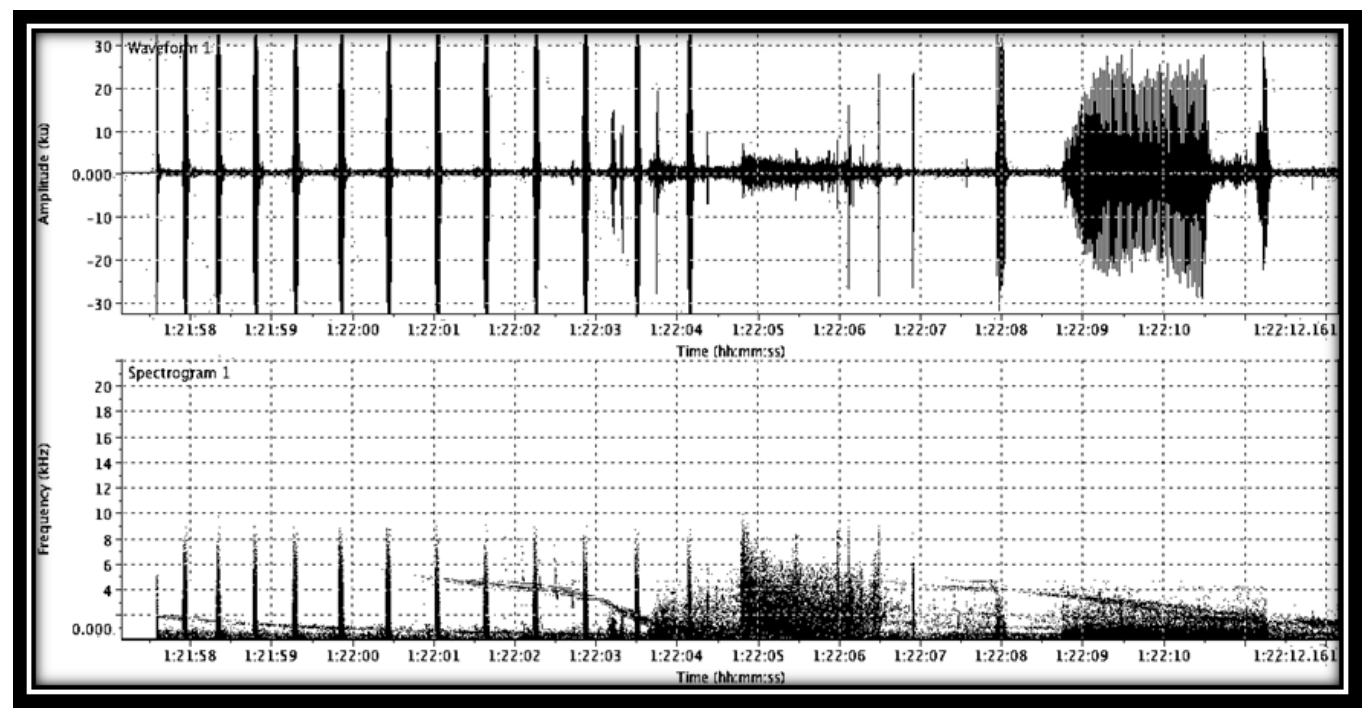

Figure 1.1. M1 chirped 12 times at which time F2 left the hole. Between 1:22.04 to 1:22.07s F2 aggressed against M1 with jaw claps and an attempted bite. At this point, M1 growled and left the visual field.

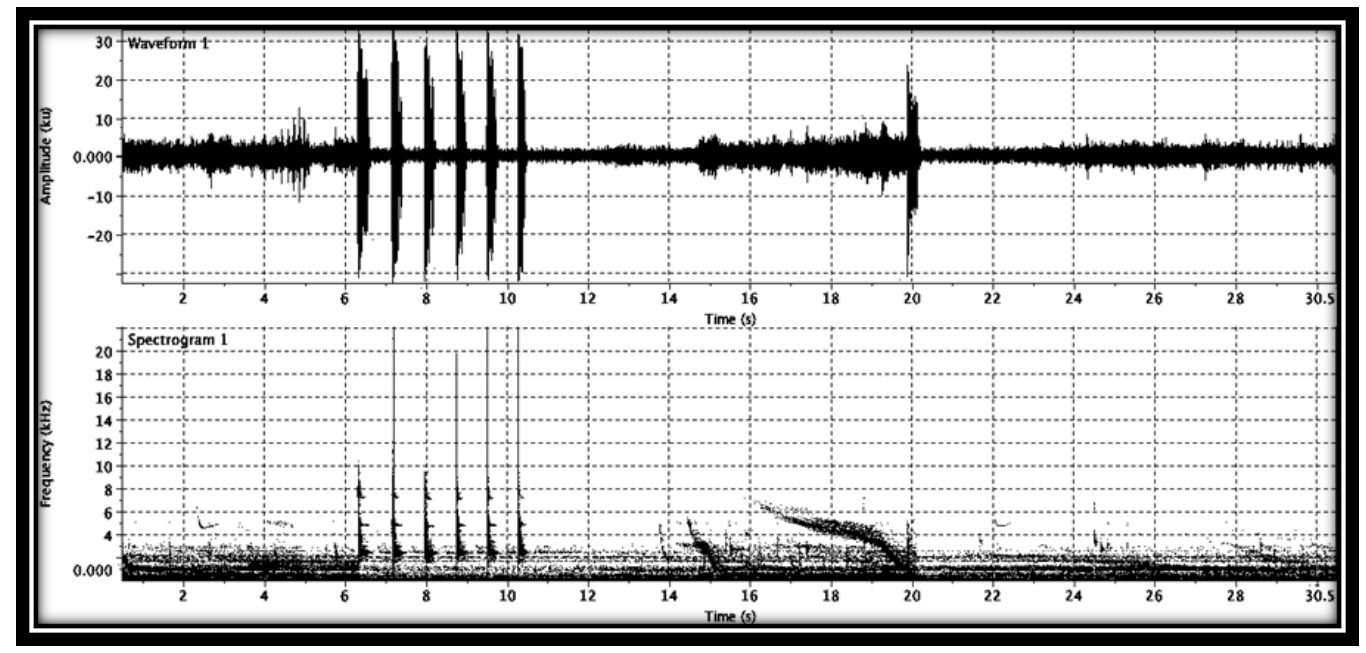

Figure 1.2. F1 chirps six times between 6 and $11 \mathrm{~s}$ while in the presence of M1. 


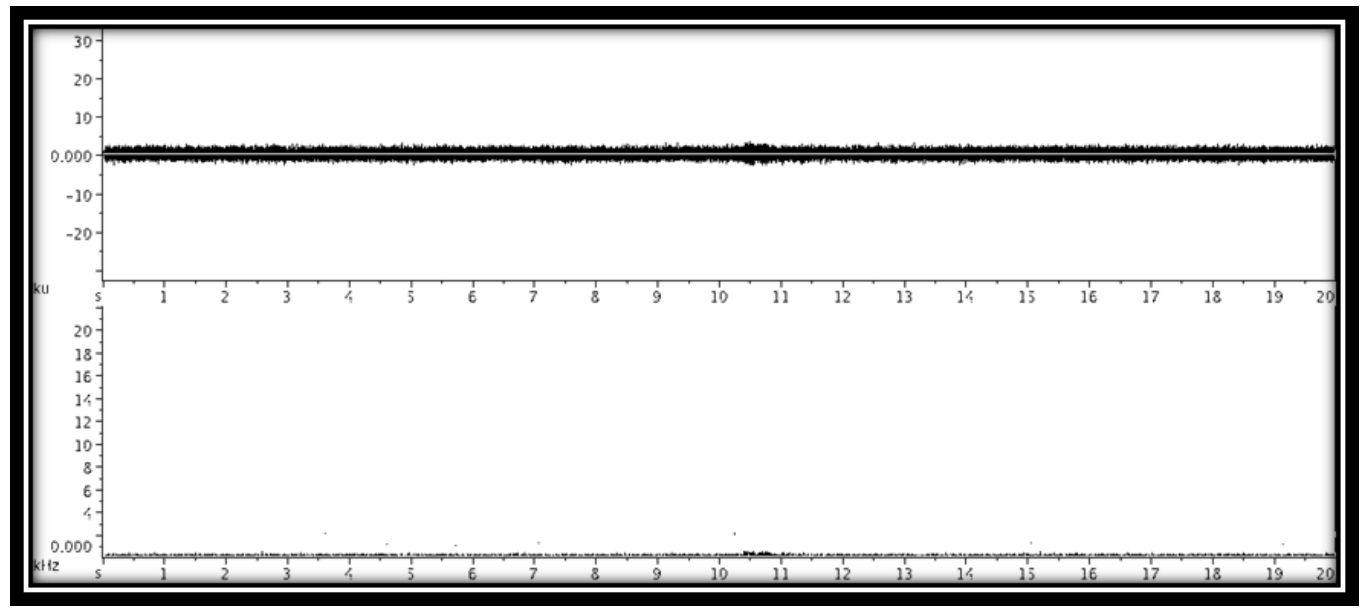

Figure 1.3. M1 mews at $10 \mathrm{~s}$. The dark line near the 0.00 frequency point between 10 and $11 \mathrm{~s}$ depicts this low amplitude, low frequency call.

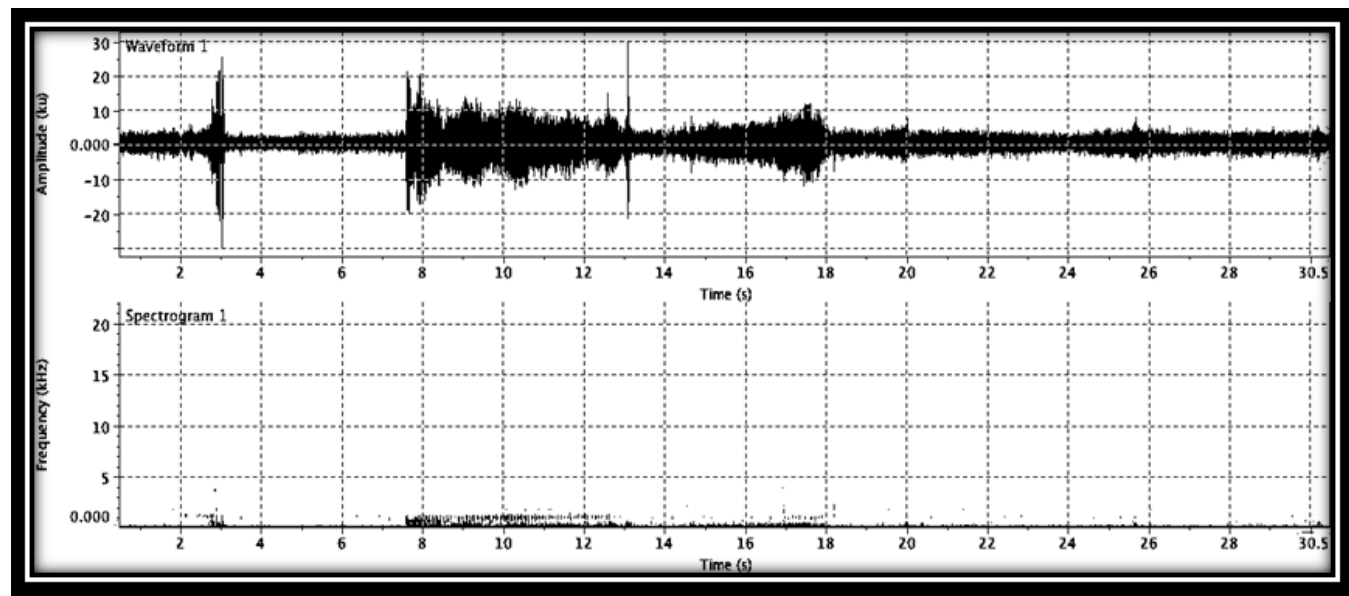

Figure 1.4 M1's growl started just after $7 \mathrm{~s}$ and ended at $18 \mathrm{~s}$.

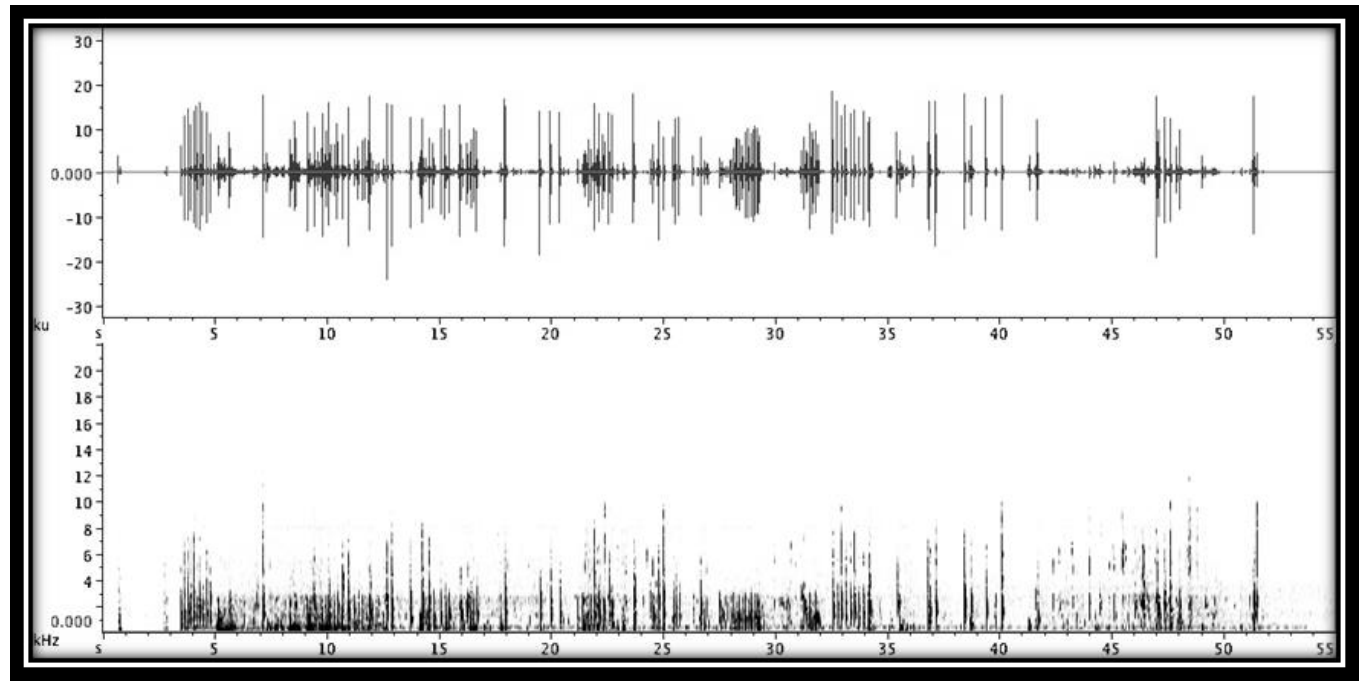

Figure 1.5. A male was released in M1's territory. Jaw claps and biting began at $3 \mathrm{~s}$; at $5 \mathrm{~s}$ there was a brief growl by M1 followed by numerous jaw claps and bites. Chirps by either seal were produced between $27-30 \mathrm{~s}$ and 31-32 s. More jaw claps and/or bites followed. 


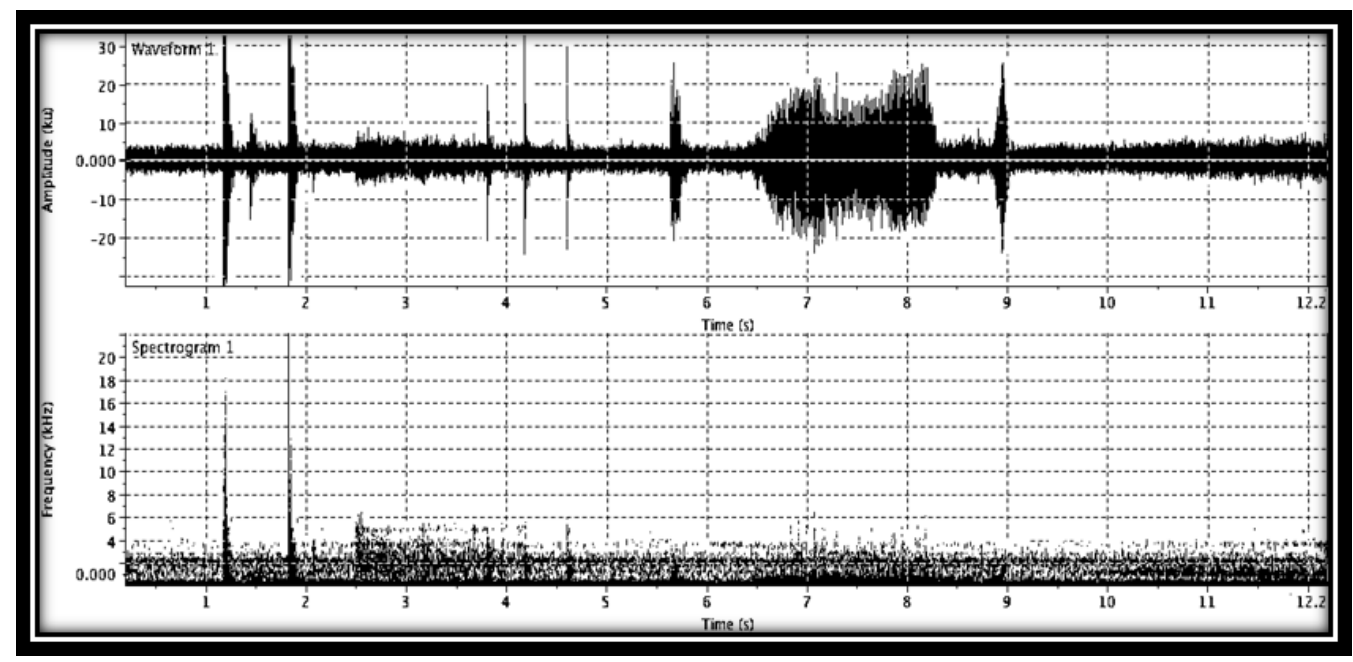

Figure 1.6. M1 completes a long series of chirps with the last two occurring between 1 and 2 s. Just before 4 s, F2 vacated the hole and encountered M1 whereupon she emitted three jaw claps and possibly bit M1. At this point M1 emitted a 2 s growl starting just before $7 \mathrm{~s}$ and left the area.

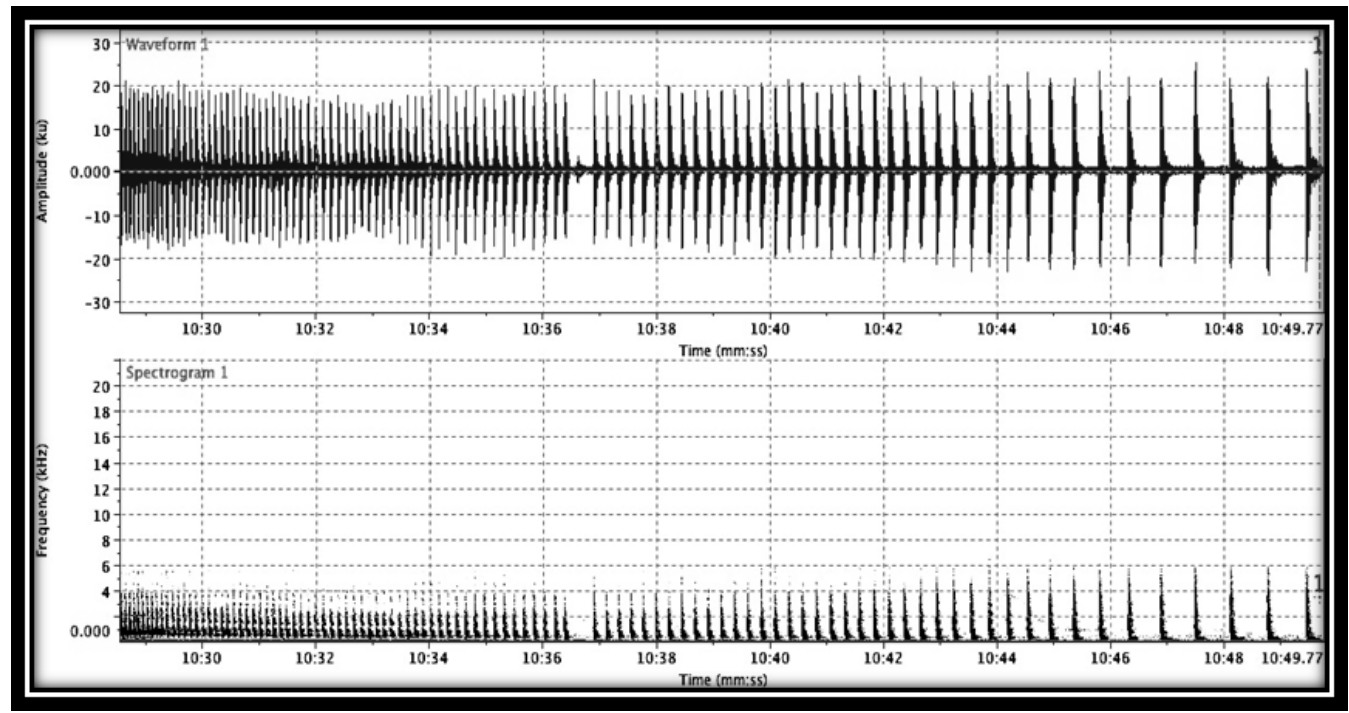

Figure 1.7. Following a brief trill, M1 knocks in the presence of F1 and F2. 


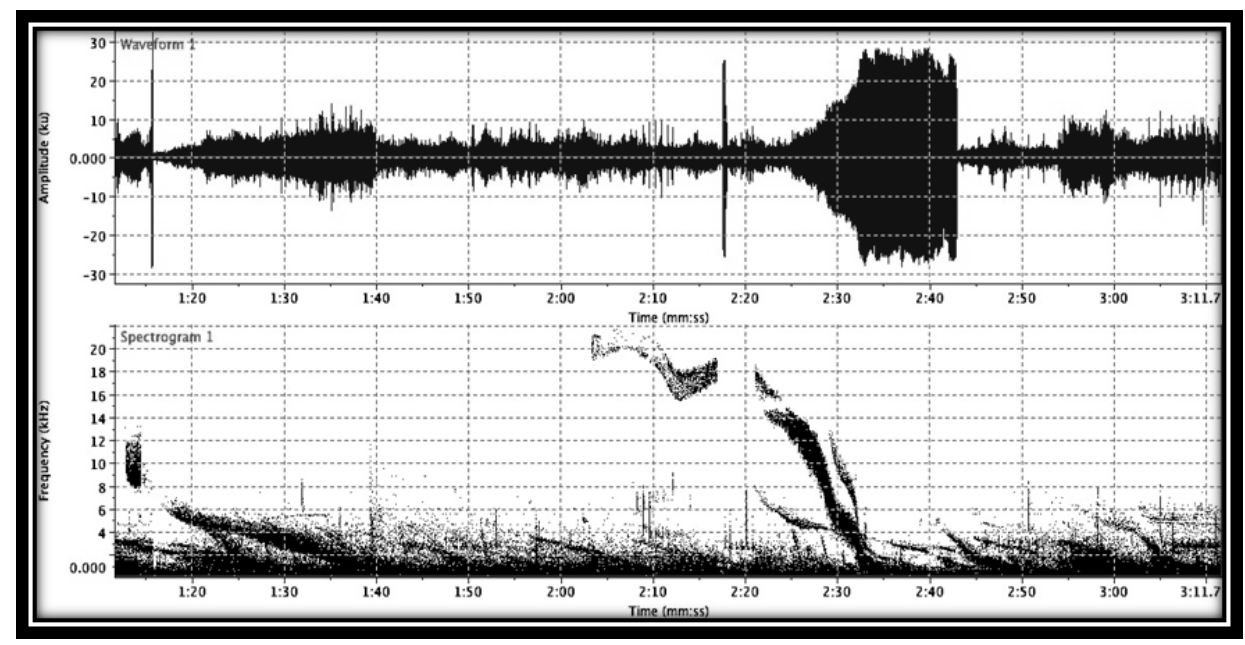

Figure 1.8. M1 trilled, stopped, female chirped four times while M1 continued his trill (Vocal category T6 from Thomas \& Kuechle (1982)). Note upper frequencies of the trill prior to the stop at 2:17 - 2:21. This portion of the call was not included in the T6 sonogram presented by Thomas \& Kuechle (1982).

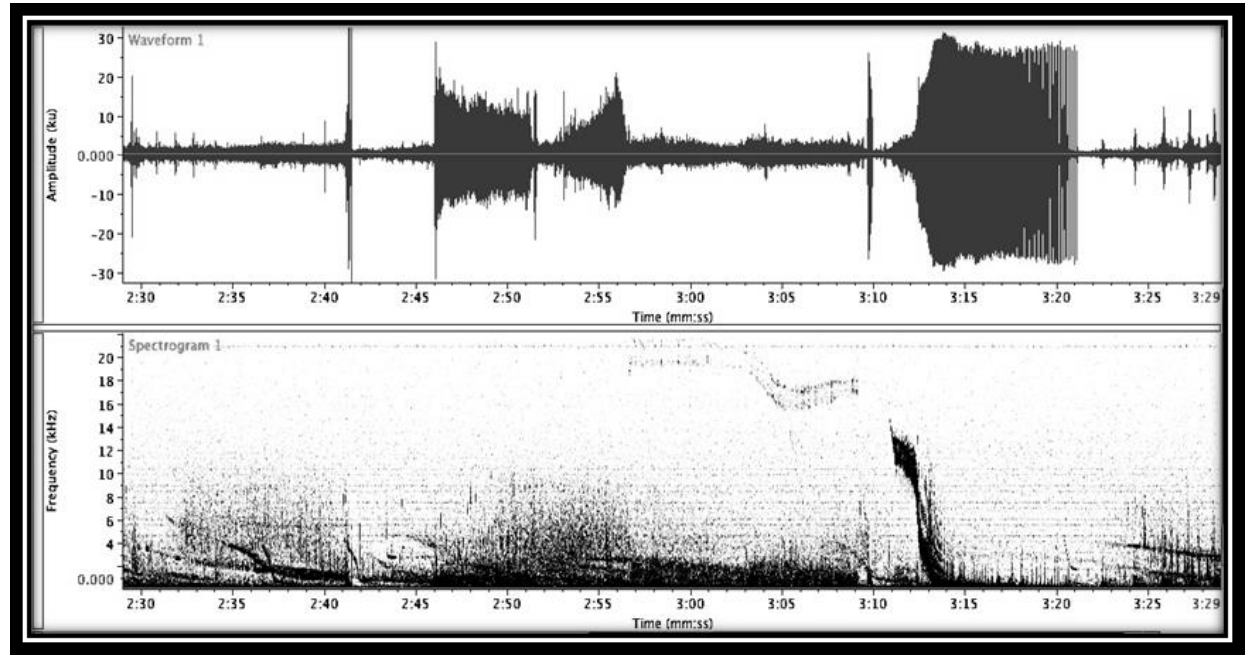

Figure 1.9. M1 growled beginning at 2:46, then trilled, followed by knocks. This is the same call type as depicted in Figure 1.8 except knocks were added (Thomas \& Kuechle, 1982).

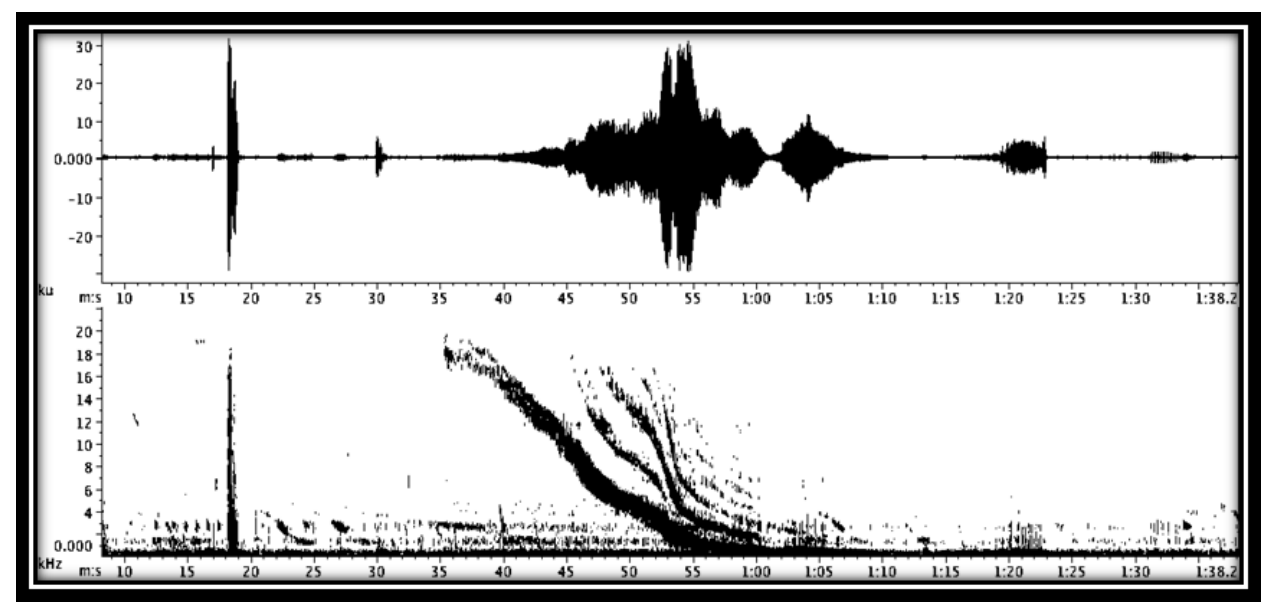

Figure 1.10. Female chirps from 13 - 18 s, M1 chirps between 18 and 19, M1 mews briefly at 30 s, and the trill becomes visible between $35 \mathrm{~s}$ and $1 \mathrm{~min} 10 \mathrm{~s}$. Note the harmonics with this trill, Trill T8, Thomas \& Kuechle (1982). 


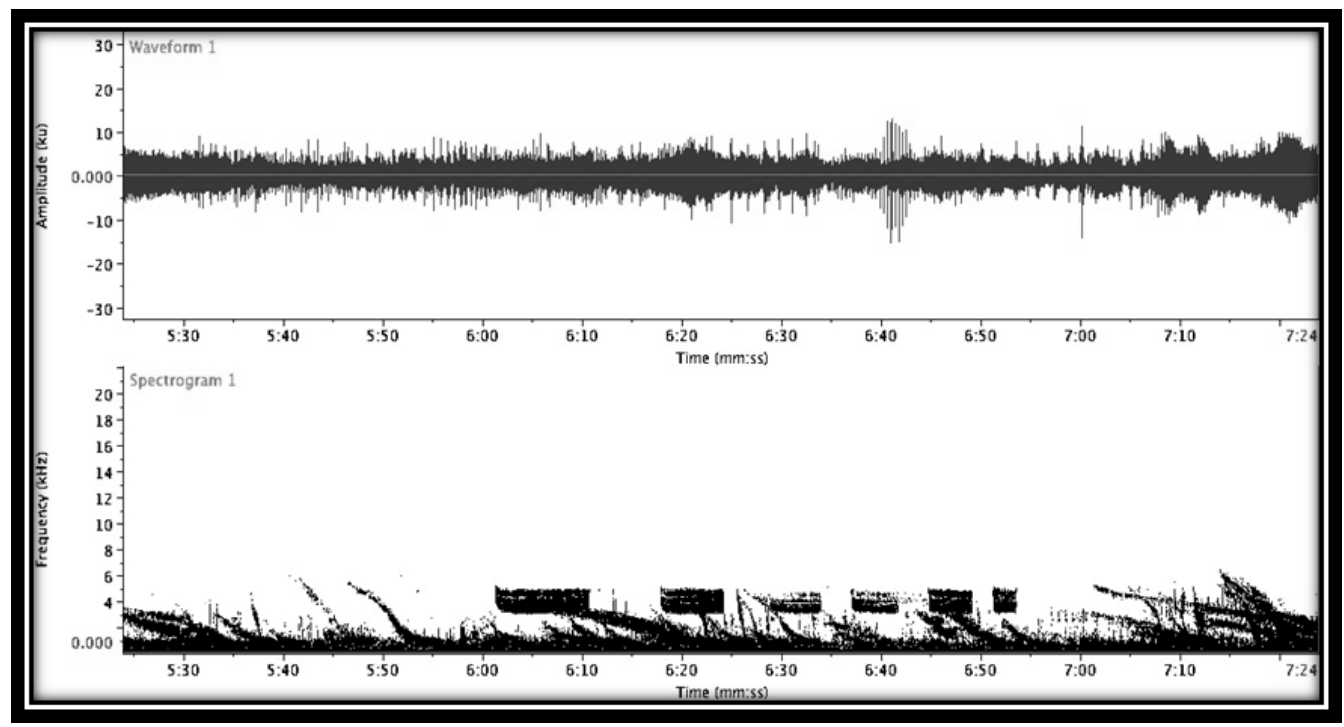

Figure 1.11. M1 produced a series of six low frequency cricket calls, R3 calls, Thomas \& Kuechle, (1982).

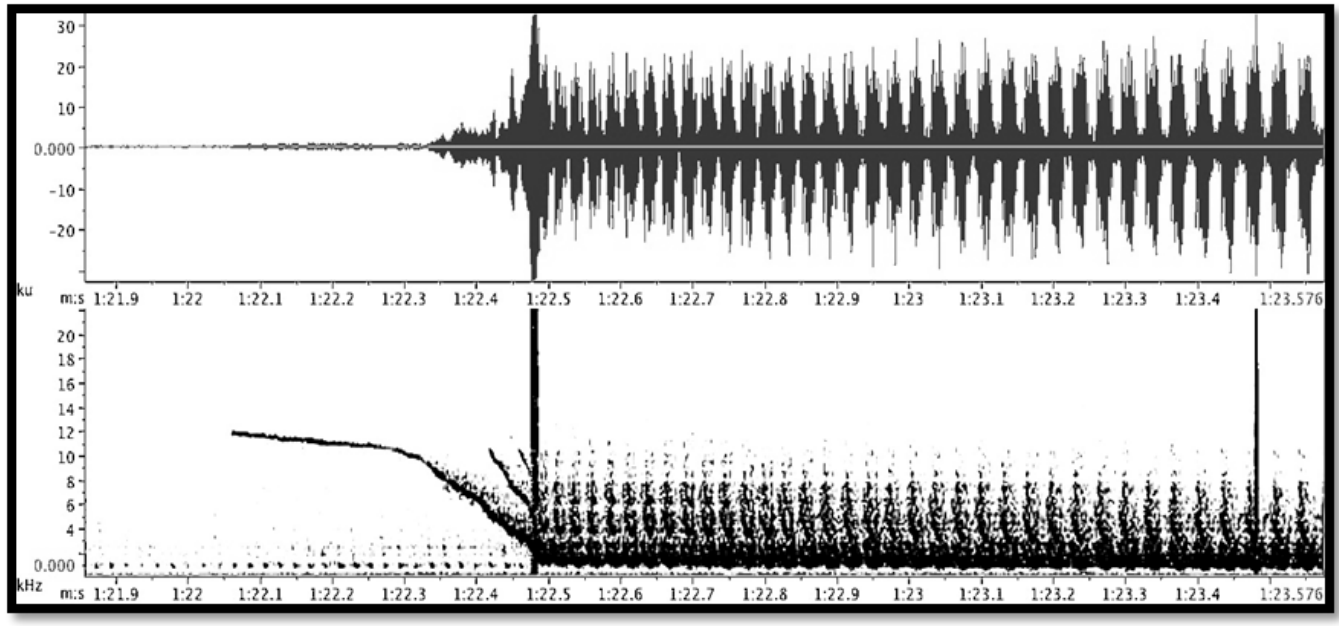

Figure 1.12. M1's vocal display to F1, F2, and a third female, 1596, that joined the group about halfway through M1's vocal display. This display was observed several times and consisted of a high frequency mew-like vocalization, trill with harmonics, then successive high-amplitude thumps or knocks.

\section{Results}

\section{Sex Differences in Vocalizations}

A total of 10,474 vocalizations and 3,792 non-vocal behaviors were identified. To test H1 the total number of vocalizations produced by M1 and F1 and the number of different vocal categories produced by each seal were compared. M1 produced 3,303 calls compared to 721 calls for F1. In addition, M1's vocal repertoire, which included chirps, cricket calls, growls, jaw claps, knocks, mews, trills, and trills + knocks, was 4-fold greater than that of F1 whose vocalizations were limited to chirps and jaw claps. To determine whether the greater number of vocalizations for M1 was attributable to vocal rate or vocal repertoire, the rates for the two vocalizations shared by M1 and F1 were compared. M1 averaged 9.5 chirps per 15 min interval over all social contexts whereas F1 averaged 17.2. Similarly, M1 averaged 1.8 jaw claps per interval over all social contexts compared to 3.9 for F1. These data suggested that the greater number of vocalizations produced by M1 resulted from his larger vocal repertoire and not the rate at which he emitted these vocalizations. 
Figure 2a: CHIRP

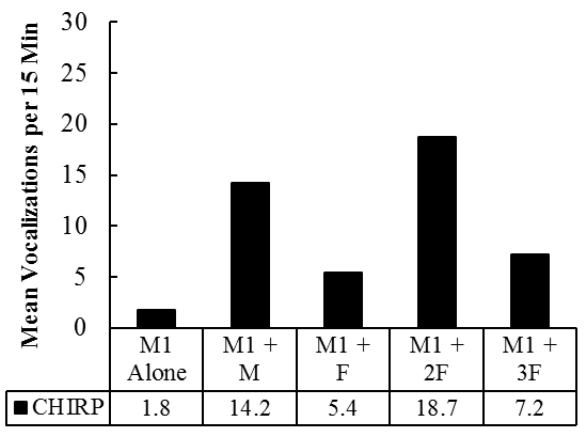

Figure 2c: GROWL

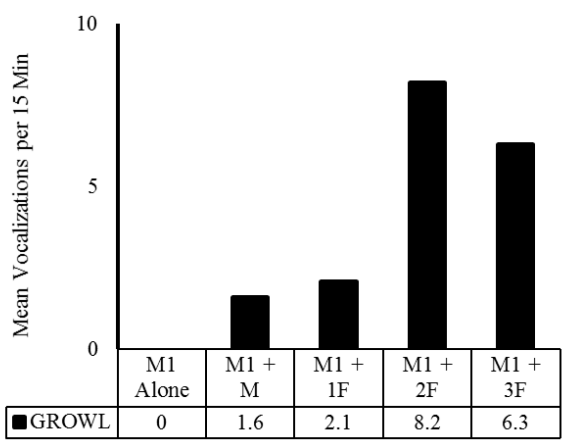

Figure 2e: KNOCK

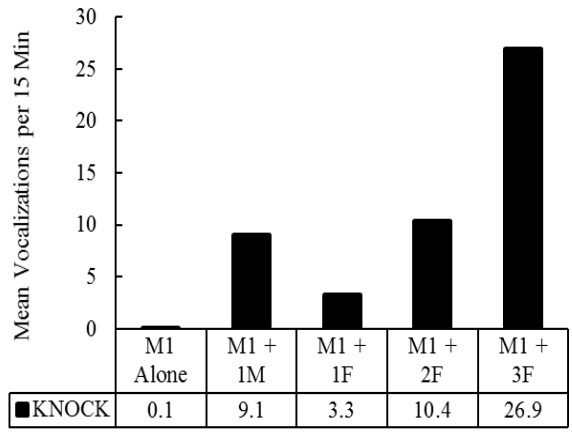

Figure 2g: TRILL

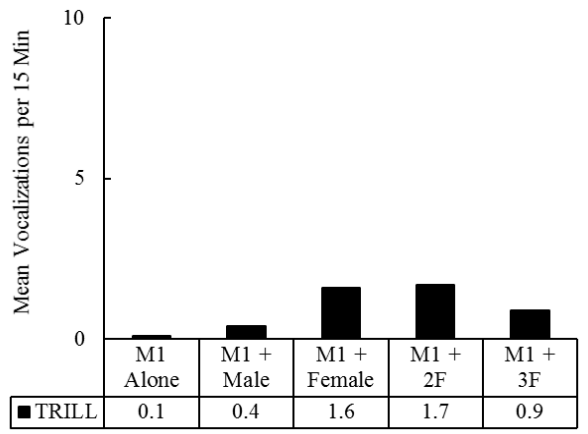

Figure 2b: CRICKET CALL

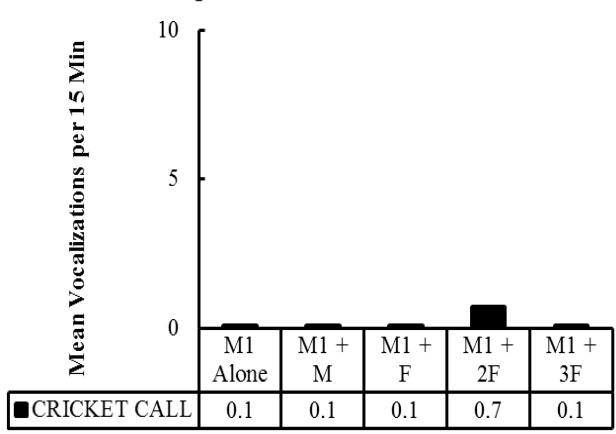

Figure 2d: JAW CLAP

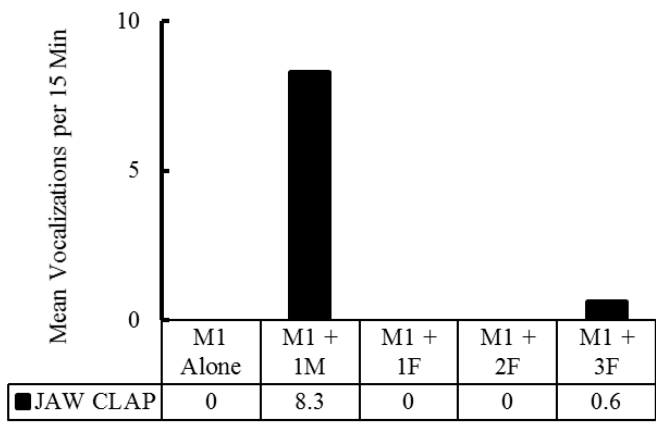

Figure 2f: MEW

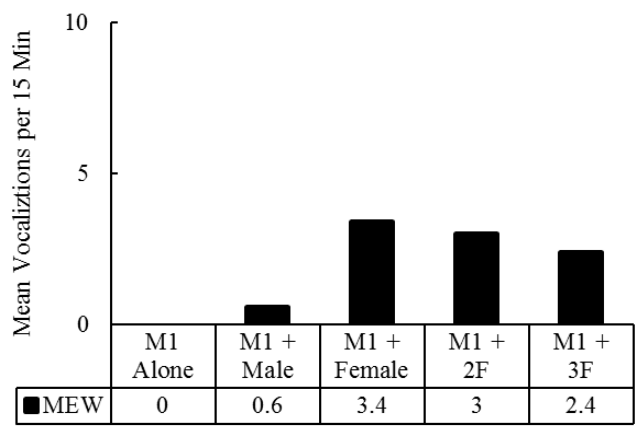

Figure 2h: TRILL + KNOCKS

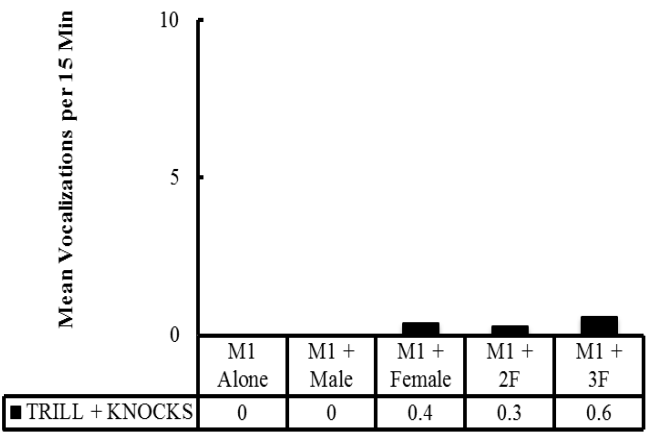

Figure 2. Mean frequency per $15 \mathrm{~min}$ interval of all vocalizations emitted by M1, the focal male. Please note the different response rate scales for Chirps and Knocks. Response rates for these two vocalizations were nearly three-fold greater than those of the remaining six. 


\section{Effects of Social Context on the Focal Male's Vocalizations}

A Chi-Square Test of Maximum Likelihood revealed that M1 distributed his calls as a function of social context, $X^{2}(28)=63.21, p<0.001$. To determine more specifically how M1 distributed his calls chi-square tests were computed for each vocal category. An assumption of equal distribution of calls across social contexts provided the expected values. Social context significantly affected all vocal categories except cricket calls, $X^{2}(4)=0.43, p=0.98$. Figure 2 depicts the mean number of M1's vocalizations across all social contexts for each vocal category. M1 produced chirps, $X^{2}(4)=10.61, p<$ 0.030 and knocks, $X^{2}(4)=20.84, p<0.001$, when other seals occupied his territory but not when he was alone. M1 emitted more jaw claps in the presence of a male than when he was alone or with one or more females, $X^{2}(4)=10.14, p<0.040$. Growls, mews, trills, and trills + knocks were produced most often when females were in M1's territory. The distributions of calls within these vocal categories did not differ one from the other, $X(12)=3.72, p<1.000$.

Kruskal-Wallis tests were used to determine the direction of those differences and Mann-Whitney $\mathrm{U}$ tests provided post-hoc analyses when needed. The number of females in M1's territory did not affect the frequency of his vocalizations within any vocal category. Consequently, Kruskal-Wallis tests were limited to social contexts M1 alone, M1 with a male, and M1 with a female.

The Kruskal-Wallis test for chirps was significant, $H=8.5, p<0.015$, and Mann-Whitney $U$ tests revealed that M1 produced more chirps when a male was present than when he was alone, $U=8.0, p<$ 0.005 , Cohen's $d=4.47$. The frequency of jaw claps also differed across social contexts, $H=8.9, p<$ 0.012 . M1 produced more jaw claps when a male was present than he did when he was alone, $U=22.5, p$ $<0.030$, Cohen's $d=1.52$, or with a female, $U=22.5, p<0.030$, Cohen's $d=1.52$. Social context also affected M1's use of growls, $H=9.7, p<0.009$, and mews, $H=13.5, p<0.001$. M1 growled more when either a female, $U=9, p<0.003$, Cohen's $d=1.26$, or a male, $U=22.5, p<0.030$, Cohen's $d=0.79$, were present in his territory. Similarly, M1 mewed more with a female, $U=9.0, p=0.002$, Cohen's $d=$ 1.77 , or a male present, $U=13.5, p<0.012$, Cohen's $d=1.20$, than he did when he was alone. Finally, the rates for trills, $H=9.6, p<0.009$, and trills + knocks, $H=6.5, p<0.040$, differed significantly. When a female was present, M1 produced more trills, $U=11.5, p<0.006$, Cohen's $d=0.95$, than when he was alone. No other differences were significant.

\section{Effects of Social Context on the Focal Female's Vocalizations}

Social context also influenced the focal female's vocalizations, $X^{2}(2)=9.89, p<0.007$. Individual chi-square tests showed that F1 distributed her chirps equally in the presence of males or females, $X^{2}(2)=$ 4.44, $p<0.108$. However, F1 emitted jaw claps only when M1 and two other females were in M1's territory, $X^{2}(2)=11.67, p<0.003$. Figure 3 depicts F1's mean vocalization rates for chirps and jaw claps across three social contexts. Only F1's jaw claps reached significance, $H=6.83, p<0.04$. F1 jaw clapped only when she and two other females were with M1, $H=6.83, p<0.04$. A Mann-Whitney U test revealed that her jaw clap rates "F1 + M1" and "F1 + M1 + F+ differed from "F1 + M1 +2 F," but not from each other, $U=0.0, \mathrm{p}<0.001$, Cohen's $d=1.82$ for both comparisons. No other significant differences in vocalizations were found.

\section{Effects of Social Context on the Focal Male's and Focal Female's Non-vocal Behaviors}

Social context had limited effects on M1's and F1's non-vocal behaviors. Among M1's event behaviors only biting changed significantly, $H=6.5, p=0.039$. In the samples analyzed, M1 bit intruding males at the rate of 2.2 bites per 15 min interval. In contrast M1 never bit a female. Although the KruskalWallis test was significant, with the low response rate for biting and high error variability for biting, Mann-Whitney U comparison tests did not reach significance. There were no significant differences (Kruskal-Wallis test) in the mean time spent swimming and resting for "M1" vs. "M1 + M" vs. "M1 + F." The number of females did affect the time M1 spent resting, $H=7.63, p=0.022$. M1 rested more when 
three females occupied his territory than he did when two females were present, $U=12.0, p=0.011, d=$ 7.53 .
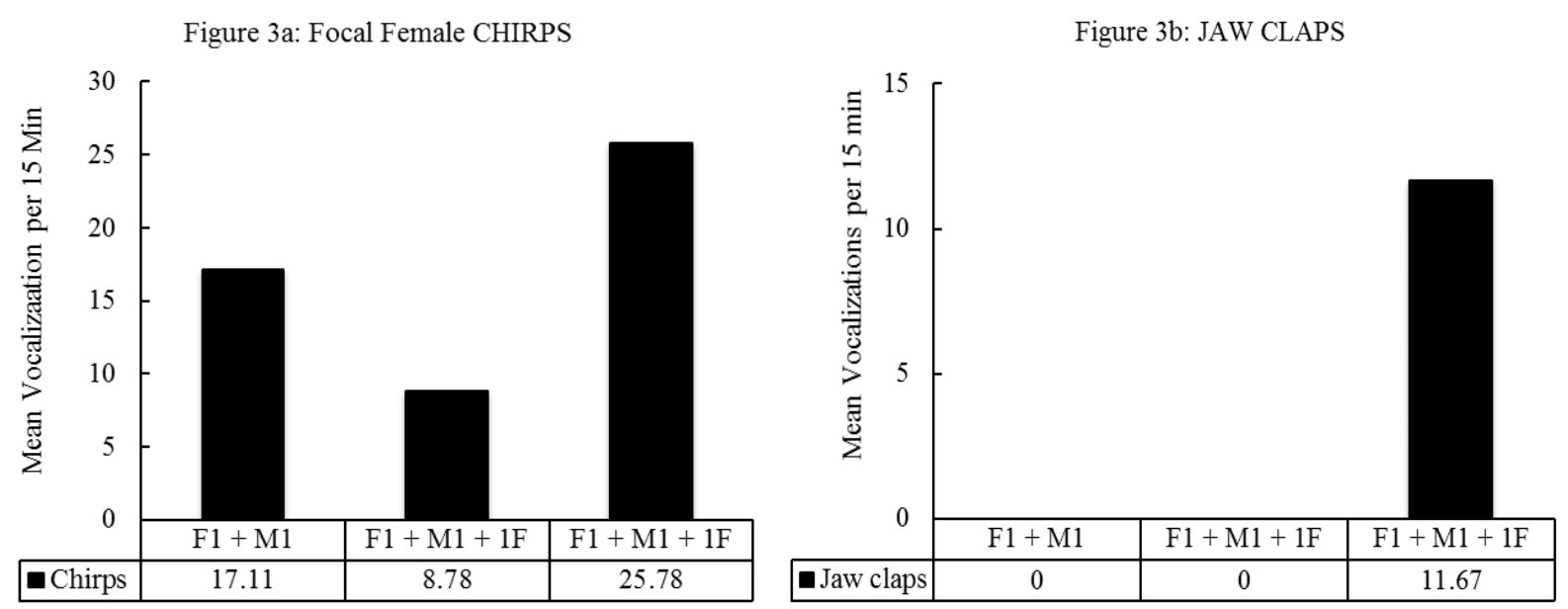

Figure 3. Mean frequency per 15 min interval of all vocalizations emitted by F1, the focal female. Please note the different response rate scales for each vocalization.

\section{Behavioral Patterns}

Theme detected a great number of significant behavioral patterns that were initially categorized as vocalization/vocalization, non-vocal/non-vocal, and vocalization/non-vocal behavioral sequences. Next we limited these significant patterns to those that represented the majority of behavioral sequences and that differed as a function of social context. Finally, we picked only those significant behavioral sequences that provided insight into the function of the various calls emitted by M1, F1 and their conspecifics. Duplicate patterns that differed only in terms of the actors involved or that were subsets of longer sequences were not considered. Table 3 shows the behavioral patterns that Theme detected and that met our criteria.

Table 3

Behavioral Sequences between M1 and Females

\begin{tabular}{lcc}
\hline Behavioral Sequence & Occurrences & Recordings \\
\hline M1 trills; M1 arrives & 89 & 12 \\
M1 leaves; M1 trills & 51 & 7 \\
M1 trills; F1 breathes \& rests & 16 & 3 \\
Female rests \& breathes; M1 trills; Female leaves & 20 & 3 \\
Female rests \& breathes; M1 trills; Female leaves; M1 swims toward hole; M1 arrives \& rests; M1 & 25 & 2 \\
leaves; Female swims towards hole, arrives \& rests & 64 & All \\
F1 leaves; M1 arrives \& rests & 16 & 3 \\
M1 growls as female leaves; or as Female swims away from hole & 113 \\
With female(s) present, M1 mews at least once; M1 trills & 16 & 18 \\
With female(s) present, M1 trills; M1 knocks once & 3 \\
\hline
\end{tabular}

Note. Shown are sequences of vocal and non-vocal behaviors that occurred together at rates greater than chance $(p<0.05)$. Semicolons indicate a short interval of time and either a different behavior or a different actor. 
With continued observations we became aware of behavioral sequences that appeared to occur repeatedly. For example, if M1 emitted a long and loud trill shortly thereafter we could expect him to enter the hole to breathe. With time we noticed that under certain conditions the seals were combining these patterns into longer sequences. Common examples included the following. 1) With a female occupying the hole, M1 trilled, entered the area under the hole, and then growled as the female left the hole allowing M1 to breathe. After a short rest M1 trilled and then left. As he did so, the female returned to the hole. 2) With one or more females in the hole breathing and resting, M1 emitted a mew, a growl, and a loud and long duration trill that ended with a series of high-energy knocks or thumps (see Figure 1.12). During this combination of vocalizations M1 would enter the area underneath the hole. At the conclusion of this vocal display, M1 would slowly swim away or, if the females vacated the hole, he entered the hole and breathed. Interestingly, regardless of whether the females were in the hole or waiting underneath it or some combination of these two locations, no female left the area until M1 stopped vocalizing. When a male intruder entered M1's territory the behavioral patterns were markedly different. When the male intruder exited from the hole, M1 would growl, jaw clap and immediately engage the intruder in a violent fight during which both males would bite each other's fore flippers, chests, genital regions, and hind flippers. Vocally, chirps and jaw claps predominated during these altercations. If the intruding male returned to the hole, M1 would not follow, allowing the intruder to breathe. This "timeout" ended when the intruder left the hole at which point M1 continued the fight with the same vigor.

The third hypothesis also predicted that the behavioral patterns that Theme detected would be ritualized. Many of the patterns met the criteria for ritualized behavior with one exception considered below. In the presence of females, the mews and growls that M1 emitted before a trill could be considered attention getting (Bradbury \& Vehrencamp, 1998). The knocks that M1 added to the end of his trills, produced only in the presence of females, were stable, rhythmic, highly repetitive, and were difficult to ignore from a human standpoint. These vocal displays were remarkable in that to our human eye they easily stood out from a very noisy background of male and female Weddell seals vocalizing in the distance. Moors and Terhune (2004) argued that ritualized displays should provide a basis for individual recognition. The present data do not provide evidence for this characteristic. Although we could document differences in vocalizations between a male and a female (M1's chirps had a lower fundamental frequency than F1's chirps) and between two females, we were unable to record the eight vocalizations of M1's repertoire from two or more different males.

\section{Discussion}

M1 acquired and then defended an under ice territory that provided ready access to air via an artificial hole drilled approximately one kilometer from a breeding colony of Weddell seals in McMurdo Sound, Antarctica. Whenever a male entered M1's territory there was an immediate and aggressive fight resulting in injuries to both seals (Williams, 2003). In contrast, when a female entered his territory, M1 allowed her virtually unlimited access to the hole and he treated her with much less aggression compared to male-male interactions. M1's behaviors eventually led to the staggered entrance of three free-ranging females that used his territory to stage foraging and exploratory dives. The observed behaviors of M1 and his resident females were consistent with RDP a polygynous mating strategy wherein a male competes with other males for resources females need to reproduce and females choose males that offer their offspring their best chance to survive to reproduce (Emlen \& Oring, 1977). The present data support this interpretation and extend the literature on Weddell seal mating behavior (Freeman \& Herron, 2001; Harcourt et al., 2007; Kooyman, 1981; Le Boeuf, 1991; Thomas \& Stirling, 1983). Emlen and Oring (1977) theorized that if a male could accurately predict the cost of acquiring the resources that females needed to successfully reproduce that male would have an advantage over males that could not. Females would also benefit from knowing a male's quality. If the costs of raising offspring were high and if these costs were coupled with the absence of male parental care (Emlen \& Oring, 1977; Kooyman, 1981; Trivers, 1972), then the female's choice of a male becomes more important than the male's choice of a female. 
The evidence for male-male competition in the current study was stronger than that for female choice. Male-male competition took the form of highly aggressive and physical fights that typically resulted in injury to both combatants (Williams, 2003). Although we cannot present hard evidence of female choice, our observations offer several lines of evidence that taken together warrant further investigation of the matter. First, when M1 preceded a trill with a mew or a growl or both, and then followed that trill with very loud knocks, the combined vocalization pattern was ritualized indicating that the sender considered the message to be important (Rogers, 2003; Rogers \& Kaplan, 2002). Second, M1 only directed this display to females in his territory. Third, the significant amount of energy M1 devoted to these vocal displays (see Figure 1.12 upper half) along with the observation that his resident females always stayed for the display, serve to support the conclusion that M1 was sending an important message to the females in residence. Fourth, the staggered appearance of three free ranging females in M1's territory would be consistent with the contention that females may be comparing the different males and their territories before taking up residence in a particular male's territory.

Support for the main hypothesis that Weddell seal vocalizations played a key role in their reproductive success was obtained when the three predictions of $\mathrm{H} 1$ were confirmed. Those predictions were derived from the assumption that RDP described their mating strategy as follows: 1) the vocal repertoire of the male territory holder (M1) would exceed that of a female residing in his territory (F1), 2) M1 and F1 would vocalize more when other seals were present than when they were alone, and 3) M1 would vocalize more than F1 over the length of the study. M1 emitted chirps, cricket calls, growls, jaw claps, knocks, mews, trills, and trills with knocks, whereas F1's repertoire was limited to chirps and jaw claps. This 4-fold difference in repertoire size confirmed the first prediction and extended the findings of other researchers who had speculated that certain vocalizations of Weddell seals were gender specific (Thomas \& Kuechle, 1982; Thomas et al., 1983). Further, the finding supported the assumption that M1 needed a larger repertoire to communicate his genetic quality to females. In addition, M1 needed to communicate to males and females information regarding his size, strength, and ability to defend and maintain his territory, and he needed to communicate to male intruders that they risked serious injury if they challenge him. Evidence for this claim is considered more thoroughly when we consider the effect of social context on the rate of each vocalization below and when we consider the possible functions of each vocalization in the section on function. Suffice it to say that we used the fundamental frequency of a vocalization to determine if it were a low frequency vocalization or high. We argue below that low frequency vocalizations can provide honest information to a recipient relative to the vocalizers size. The differences in the number of vocalizations emitted by M1 were associated with changes in the social context and these specific differences considered below support the conclusion that M1 was sending the male intruder or the females in his territory messages that he considered were important.

M1 vocalized significantly more when other seals occupied his territory than when he was alone confirming the second part of H1. Fewer than $2 \%$ of M1's vocalizations were produced when he was alone. In contrast, more than $60 \%$ of his vocalizations occurred when two or three females occupied his territory. When one male or one female was present, M1 emitted nearly twice as many vocalizations to a male intruder as he directed toward a female. For lack of data in the F1 Alone category we were unable to verify that F1 was also more vocal in the presence of other seals than when she was alone. M1 vocalized over 4.5 times more than F1 confirming the third part of H1. Taken together the three-part hypothesis provided strong evidence that the vocalizations of Weddell seals during the breeding season played an important role in reproductive behavior.

The vocalizations of M1 and F1 differed significantly depending on the social context. M1 emitted chirps primarily when he was alone, or with another male or a female. When he was with two or more females, knocks predominated. Virtually all of M1's trills and trills + knocks were emitted when females were in his territory. Four vocalizations growls, jaw claps, mews, and trills + knocks were never heard when M1 was alone. M1 growled and emitted knocks when males and females were present, but he growled more in the presence of females. Jaw claps were reserved almost exclusively for male intruders whereas mews and trills + knocks were emitted almost exclusively for females. F1's vocalizations were also affected by the social context. F1 jaw clapped only when she was sharing M1's territory with two 
females and M1.

The evidence supporting Hypotheses 1 and 2 does not address the question why these calls were emitted in the manner they were. Although speculative, the common characteristics among these vocalizations may help to clarify their purpose. Growls, knocks, and mews were low-frequency vocalizations (see Table 2 and Figures 1.3, 1.4, 1.6, 1.7, and 1.12). Because size correlates inversely with call frequency, these vocalizations could have provided size information to the recipient (Owings \& Morton, 1998). Trills and trills + knocks were long-duration vocalizations (see Table 2 and Figures 1.8, $1.9,1.10$, and 1.12) emitted most often in the presence of females. These frequency-modulated long duration vocalizations could have encoded information regarding M1's strength and stamina. Additional clues to his quality could have come from the territory itself. If M1's trills informed females regarding M1's size, strength, stamina and reproductive success then male Weddell seals could be using trills in a manner similar to bearded seals in the arctic. Van Parijs et al. $(2003,2004)$ documented that trills emitted by bearded seal males differed depending upon their status. Bearded seals defending a territory emitted trills that were longer and covered a greater range of frequency than non-territory holders (van Parijs et al., 2003, 2004). Importantly male bearded seals with a territory were shown to have had greater reproductive success than non-territory holders.

Hypothesis 3 predicted that statistically reliable behavioral sequences would be discovered and found to differ between social contexts. And given their importance to reproductive success these behavioral patterns would be ritualized (Rogers \& Kaplan, 2002). Theme identified unique behavioral sequences emitted by M1 that consisted of two or more vocalizations, two or more non-vocal behaviors, and specific combinations of vocalizations and non-vocal behaviors. These behavioral sequences were emitted in those situations one would expect if their purpose were to recruit females his territory (Rogers, 2003). Examples of these behavioral sequences included M1 growled when a female left his territory, M1 trilled with and without knocks when females were in his territory, and M1 trilled as he returned to his territory and again as he departed. Longer sequences were also observed. M1 trilled when the female occupied the hole, as she departed M1 quickly arrived in the hole, and then as he departed, the female returned to the hole to breathe and rest. Finally, on numerous occasions, when two or more females occupied his territory with one or more females sharing the hole, M1 emitted a vocal display consisting of a short mew and/or growl, followed by a high amplitude long duration trill which was then followed by very loud knocks (see Figure 1.12).

It was not surprising that M1's vocal displays and the vocal-non-vocal combinations met the criteria for a ritualized pattern. Ritualized acts of communication have also been found in other pinnipeds, including male Australian fur seals (Arctocephalus pusillus doriferu; Tripovich, Rogers, \& Arnould, 2005 ) and the Atlantic walrus (Odobenus rosmarus rosmarus; Stirling, Calvert, \& Spencer, 1987). The ritualized sequences of vocalizations and non-vocal behaviors further supported the contention that vocalizations play a critical role in the reproductive behavior of the Weddell seal.

\section{Functional Analyses of Certain Vocalizations}

To add to the understanding of the function of a specific vocalization, we examined the relevant literature where speculations regarding the function of specific vocalizations had been made. Next, we compared M1's and F1's use of the vocalization across all social contexts. Finally, we took into account those behavioral sequences of vocalizations and non-vocal behaviors that included the vocalization of interest and that Theme showed to be statistically significant. Thomas et al. (1983) proposed that chirps were non-aggressive vocalizations signaling to another seal 'submission' or 'no intent to harm' (Thomas, 1991). This hypothesis would make different predictions depending on social context. First, chirps should not be made when M1 was alone. Second, if a female entered his territory chirps should abound because M1 would be motivated to assure the female that she would not be harmed. Third, if a male entered M1's territory, M1 should chirp only if the intruder was winning or was going to win a challenge to his territory. These predictions were not supported. M1 produced more chirps than any other vocalization except for knocks. Even when he was alone, M1 averaged nearly two chirps per 15 min interval. 
Whenever M1 encountered a male intruder, his rate of chirping abruptly increased to nearly once a minute even though the intruder was leaving or had left his territory. And when a female entered his territory M1 averaged just over 5 chirps per sample. The submission hypothesis cannot account for M1's chirps when he was alone, or why M1 increased by 8 -fold the number of chirps he made during a challenge that he was winning or had won. In addition, the submission hypothesis cannot account for why M1 reduced his chirp rate $67 \%$ in the presence of a female relative to the presence of a male intruder. At this point we need to qualify the conclusion that chirps were not used to indicate submission. One of the lines of evidence we drew upon was the number of chirps produced when M1 was with a male intruder. Figure 2 documents that M1 produced 14.2 chirps per interval compared to 1.8 when he was alone and 5.4 chirps per interval when he was with a female. It was possible that we over or under estimated the mean number of chirps because in some instances when both males in under the hole and in view it was possible to misidentify the vocalizer. Whereas we could visually distinguish M1 from the intruder, it was more difficult to assign ownership to the vocalization rate. Specifically, with respect to chirps, when both males were chirping we were unable to assign the exact number of chirps heard to M1. In these instances, we averaged the number of chirps and assigned that to M1. If, and we do not consider this was likely, the male invader produced all of the chirps the result would provide support for the submission hypothesis. That said, the chirp rates for the other four social contexts do not the support the submission hypothesis.

Other researchers have argued that chirps served a different function. Watkins and Schevill (1968) noted that chirps were commonly heard when seals were swimming from one breathing hole to another and hypothesized that their function was related to inquiry and navigation. Watkins and Schevill's hypothesis could account for M1's chirps. When M1 was alone, his chirps could have signaled seals outside his territory both his presence and his location. In the presence of a female M1's chirps could have continued to signal his presence and they might have provided directional cues to his hole (Kooyman, 1981). When a male entered his territory M1's chirps could have served to maintain contact and keep the intruder apprised of his location possibly informing the intruder's exit strategy.

F1's chirps also fit this role. Over all social conditions F1 averaged 17 chirps per 15 min interval, the highest average rate for any vocalization for either sex. The highly aggressive nature of the male defending his territory combined with the female's need for ready access to a hole in the ice support the hypothesis that a signal announcing her presence and her location would be beneficial to both parties. Figures $1 \mathrm{a}$ and $1 \mathrm{~b}$ revealed that F1's chirps were emitted at a higher frequency than M1's raising the possibility that M1 could have known that a female was in his property when he heard her chirp. And if chirps were specific to the individual then M1 could have known that F1 was in his territory. Either way, knowing that an intruder is female, M1 could have reduced his aggressive behavior and enacted courtship behaviors earlier. As a result, the female would be less likely to be injured by mistake and the male would be more likely to mate successfully. Again, we need to qualify this conclusion. When F1 was with one or more females who were all chirping, it was difficult at times to assign the correct number to F1. In this case, we once again used the average rate across all vocalizers in the sample. That aside, over or under estimating the number of chirps F1 emitted would not have affected our conclusion that chirps by the female were not made as a gesture of submission. We could use the fundamental frequency to determine whether M1 or F1 produced the chirp, thus the confusion was only possible when two or three females shared the hole with M1. In this case the important statistic is that M1 could determine the presence of females in his territory regardless of the exact number of chirps the female made. In this case the conclusion was the same whether F1 produced all of the chirps or none of the chirps when she was haring the hole with M1 and one or two others.

The use of vocalizations to inquire, maintain contact, and/or aid navigation has been documented in insects and amphibians (Mhartre \& Balakrishnan, 2006), birds (redwing blackbirds, Peek, 1972; Carolina wrens, Owings \& Morton, 1998), and other mammals (wolves, Harrington, 1979, 1987). Although vocalizations were not involved, the findings from experimental work with fishes are relevant. Experiments with blue gouramis (Trichogaster trichopterus) have established that if the normally aggressive male is presented a neutral stimulus that signals the male that a female will soon enter his territory, the male becomes less aggressive more quickly, courtship begins earlier, and the resulting 
mating yields more fry compared to blue gouramis in the control group. These results from Hollis, Pharr, Dumas, Britton, and Field (1997) were the first to show that a reliable signal informing a male that a receptive female was about to enter his territory could enhance the reproductive success of the male and the female (Hollis, Cadieux, \& Colbert, 1989; Hollis et al., 1997). Obviously caution is needed when extrapolating from fishes to mammals, but Hollis' (1997) results raise the possibility that a cue reliably signaling a male Weddell seal that a receptive female is about to enter his territory has the potential to enhance the reproductive success of both parties. Overall, the interpretation that chirps acted as contact calls indicating the sex, direction, and location of the chirping individual provided the best account of our results.

Table 2

Total Calls per Category and Brief Definition Based on Thomas \& Kuechle (1982)

\begin{tabular}{|c|c|c|c|}
\hline Call Category & Total Calls & $\begin{array}{c}\text { Thomas \& } \\
\text { Kuechle (1982) }\end{array}$ & Acoustical Characteristics of the Vocalizations Observed and Analyzed \\
\hline Chirps & 6,431 & $\mathrm{P}$ & $\begin{array}{l}\text { Short duration }(<1 \mathrm{~s}) \text { broadband calls }(0-8 \mathrm{kHz}) \text { emitted by M1 (Figure } \\
1.1) \text { and F1 (Figure } 1.2) . \mathrm{F} 1 \mathrm{chirps} \text { had a higher frequency with most } \\
\text { chirps ranging from } 2-22 \mathrm{kHz} \text {, the upper limit of our recording device } \\
\text { (44 samples/s). }\end{array}$ \\
\hline Mews & 1,077 & M & $\begin{array}{l}\text { Short duration }(<1 \mathrm{~s}) \text { low frequency }(0-1 \mathrm{kHz}) \text { low amplitude calls } \\
\text { produced only by males in our samples (Figure } 1.3) \text {. }\end{array}$ \\
\hline Growl & 885 & $\mathrm{~L}$ & $\begin{array}{l}\text { Long duration }(3-11 \mathrm{~s}) \text {, low frequency, broadband calls }(0-2 \mathrm{kHz}) \text { with } \\
\text { high amplitude. Growls were specific to males in our samples (Figure 1.4) }\end{array}$ \\
\hline Jaw Claps & 567 & $\mathrm{H}$ & $\begin{array}{l}\text { Short duration }(<0.3 \mathrm{~s}) \text {, broadband sounds }(0-8 \mathrm{kHz}) \text { produced when a } \\
\text { seal opened its mouth widely then quickly brought the lower and upper } \\
\text { jaw together. Whereas not strictly speaking a vocalization, Thomas \& } \\
\text { Kuechle }(1982) \text { classified them as vocalizations and we followed their } \\
\text { system. The broadband range was not as great for females }(0-6 \mathrm{kHz}) \\
\text { (Figures } 1.5,1.6) \text {. }\end{array}$ \\
\hline Knocks & 548 & $\mathrm{~K}$ & $\begin{array}{l}\text { Short duration }(<1.0 \mathrm{~s}) \text {, broadband vocalizations }(0-4 \mathrm{kHz}) \text { specific to } \\
\text { males. Knocks were very high amplitude vocalizations (Figures } 1.7,1.12 \text { ) }\end{array}$ \\
\hline Trills & 524 & $\mathrm{~T}$ & $\begin{array}{l}\text { Long duration frequency modulated vocalizations that typically started at } \\
\text { a high frequency and then decreased in frequency over time. Trills were } \\
\text { often appended by pre and/or post vocalizations. Trill duration ranged } \\
\text { from } 4.5-45 \mathrm{~s} \text { and the frequency ranged over } 15 \mathrm{kHz} \text { in certain trills. } \\
\text { (Figures } 1.8,1.9,1.10 \text { ). Only males emitted trills. }\end{array}$ \\
\hline Cricket Call & 270 & $\mathrm{R}$ & $\begin{array}{l}\text { Long duration }(3-9 \mathrm{~s}) \text {, relatively narrow broadband calls with a } \\
\text { frequency range from } 3-5 \mathrm{kHz} \text { and moderate amplitude. (Figure 1.11). In } \\
\text { our samples this vocalization was male specific. }\end{array}$ \\
\hline Trill + Knocks & 154 & $\mathrm{~T}$ & $\begin{array}{l}\text { Long duration, frequency modulated call with high amplitude knocks } \\
\text { added at the end. This male only acoustic display was only observed when } \\
\text { females were present (Figure 1.12). }\end{array}$ \\
\hline
\end{tabular}

Unknown

Jaw claps (H call; Thomas \& Kuechle, 1982) were produced when M1 or F1 rapidly and repeatedly brought their upper and lower jaws together. Thomas et al. (1983) interpreted this vocalization as a high intensity threat. This hypothesis was strongly supported. M1 never emitted jaw claps when he was alone or with one or two females. In fact, M1 only jaw clapped when three females occupied his 
territory. In contrast, when a male was present, M1's rate of jaw claps increased nearly 14-fold compared to the rate when three females were in his territory. When M1 attacked another male he typically growled, then jaw clapped, then physical violence ensued including biting and wrestling. In contrast, F1 never produced jaw claps in the presence of M1 or another female. However, she did emit jaw claps when M1 and two additional females were present in M1's territory. It is interesting to note that M1 and F1 only jaw clapped when they were in M1's territory along with two additional females. It appeared that in crowded conditions, conflict over which female was going to breathe resulted in aggressive behavior. If F1 were in the hole and another female arrived, F1 would make room. However, when a third female attempted to breathe F1 would submerge and direct jaw claps toward her often but not always causing the third female to back off.

In addition to chirps and jaw claps, M1 emitted cricket calls, growls, knocks, mews, trills, and trills + knocks. The rate of cricket calls did not change when social contexts varied suggesting that they played no role in reproductive behavior. However, the possibility remains that cricket calls could serve an equally important function for both male and female seals. Further tests are needed to establish the role of cricket calls, if any, in the reproductive behavior of Weddell seals. Social context influenced growl rates significantly, but not in the direction proposed by Thomas et al. (1983) who argued that growls constituted a low-level threat. M1 did not growl when he was alone, and in the presence of a male he averaged 1.6 growls per sample interval. However, if a female entered his territory M1's growl rate increased $33 \%$ and if two females were present his growl rate increased nearly four-fold more. If growls were low-level threats, one would have expected more growls when a male was present than when a female occupied his territory. And, unless the female was blocking M1's access to air, threatening her would seem counter-productive to his goal of mating with as many receptive females as possible. M1 growled whenever a female left his territory. This behavioral sequence also challenged the low-level threat hypothesis. As previously considered, Owings and Morton (1998) noted that low frequency vocalizations like growls (see Figures 1.1, 1.4, 1.6, and 1.9) provided honest information regarding his size. In light of this inverse relation, M1's growls could have served to repel a male and attract females.

Knocks were short duration, low frequency vocalizations. M1 produced knocks by themselves, but more often knocks followed a second vocalization, normally a trill. There were large differences in knock rates depending on social context (Figure 2), however, the considerable variability around the means for each social context precluded statistical reliability. In contrast social context did affect those instances when M1 added knock(s) to the end of his trills. The proposed function of this vocalization is discussed below.

Thomas et al. (1983) hypothesized that mews, relatively long, low frequency vocalizations, functioned as high intensity threats. This interpretation was not supported by the present data. M1 never mewed when he was alone. However, in the presence of a female M1 produced mews nearly six fold more often compared to when a male occupied his territory. Normally M1 mewed when a female arrived at the ice hole and he mewed twice before beginning a trill that coincided with his arrival at the hole. These observations suggested that mews served the same role as growls namely to gain the attention of a female and possibly provide information regarding the size and fitness of M1 (Owings \& Morton, 1998).

Trills were long duration vocalizations characterized by a descending frequency-modulated sweep (Thomas \& Kuechle, 1982). M1 trilled under all social contexts, but most often when females were present and least often when he was alone. Trills were often preceded by auxiliary calls and somewhat less frequently by post auxiliary vocalizations. Thomas et al. (1983) proposed that trills advertised that a given territory was being defended. More specifically, trills provided the location of the territory holder and served a role in territorial defense, dominance, and warning. Thomas et al. (1983) also thought that males trilled to recruit females. More recently, researchers confirmed the use of trills for territorial advertisement and defense, but proposed further that trills were used in a graded fashion with short/low intensity trills serving as a reminder whereas long/loud high intensity trills provided an emphatic warning (Dudzinski, Thomas, \& Douaze, 2002). In addition, Dudzinski et al. (2002) argued that the pre- and postauxiliary vocalizations might serve to warn or perhaps emphasize a message.

Our results supported these conclusions and provided additional details. Theme identified 
numerous patterns involving trills. In one, M1 trilled from a point outside the camera's view, then he entered the viewing area swimming straight to the hole where he breathed and rested. A second pattern began with a female occupying the hole, then M1 trilled and the female departed shortly thereafter. Once she vacated the hole, M1 entered quickly and breathed. After a brief rest, M1 trilled as he departed at which point the female returned to breathe and rest in the hole. M1's trills appeared to signal males that this territory was being defended and to females that here laid a reliable place to breathe, forage, and perhaps find a mate. Trills also appeared to announce that M1 was about to enter the hole to breathe or that he was about to leave the hole. Trills were recorded four-fold more often in the presence of females than males suggesting that trills were more for the benefit of females. Because trills of this magnitude (see example, Figure 1.12) could be heard over a large area the possibility exists that females could compare the quality of several males at the same time without having to swim from one location to the next. In that regard trills could play a very important role in Weddell seals during the breeding season. To verify this contention, researchers would need to show that individual differences exist in the male specific trills, that females can detect these differences, and that females choose the best male to sire their pups. Obviously more evidence is needed to validate the role of trills in the mating system of the Weddell seal. However, trills have been shown to correlate with reproductive success in bearded seals (Van Parijs et al., 2003, 2004) thus adding some merit to the possibility.

We identified additional behavioral sequences involving trills and auxiliary vocalizations notably growls, knocks, and mews. M1 mewed before beginning a trill, but only if one or more females were present. The same conditions held for growls, which M1 sometimes added at the beginning of a trill. Finally, M1 would add a knock or a series knocks to the end of a trill. Again, these vocalizations were heard only when females were in M1's territory. As mentioned earlier, the combination of mews, growls, and loud and long duration trills with high very high amplitude knocks (Figure 1.12) represented a ritualized vocalization-vocalization sequence that appeared to serve as an important display in the courtship behavior of the Weddell seal.

\section{Conclusions and Limitations}

Using simultaneous video and audio recordings, we assessed the role of Weddell seal vocalizations from a male and a female seal that interacted around an artificial ice hole during the breeding season. Males and females differed significantly with respect to their vocal repertoires. Male vocal categories included chirps, cricket calls, jaw claps, growls, mews, knocks, trills, and combinations of growls, knocks, and mews with trills. In our samples, female vocalizations were limited to chirps and jaw snaps. With the exception of cricket calls social context determined the use of vocalizations and this finding formed the basis for functional analyses of male and female vocalizations. We concluded that chirps served as contact calls, informing other seals about the presence and location of a conspecific. In addition, chirps could have provided directional cues enabling seals to locate holes in the ice or the whereabouts of a territory holder (Kooyman, 1981; Watkins \& Schevill, 1968). Growls from the male territory holder could have provided size and possibly fitness information for the purpose of recruiting females and repelling males. Mews were used in the same manner as growls. However, mews were directed more to females than to males. Trills appeared to announce when the territory holder was approaching or leaving the ice hole. In addition, trills may have warned males in the area that a territory was being defended. Either alone or in combination with growls, knocks, and mews, trills served to attract females. Trills were 4-fold more likely to be directed towards females suggesting that their primary role was to solicit females. The present investigation offered an improvement over previous methods attempting to assess the role of vocalizations in the reproductive behavior of Weddell seals (Pahl et al., 1996, 1997; Thomas et al., 1983).

The results confirmed three alternative hypotheses that together provided strong evidence that the vocalizations of Weddell seals during the breeding season played an important role in determining their reproductive success. However, we acknowledge that the data discussed in this paper were obtained from one focal male (M1) and primarily the three free-ranging females (F1, F2, \& F3) that shared the male's 
territory by the end of the study. The limitations of single subject experiments are well known and for that reason we attempted to increase the internal validity of our study by categorizing our data according to social context (male alone, female alone, male-male, female-female, and male-female), dividing the number of hours of video taped observations into 15-min samples, and then randomly selecting a subset of these samples for statistical analysis. In addition, we chose nonparametric statistical analyses to determine whether social context affected the use of eight vocalization types (chirps, mews, knocks, trills, etc.) or the rate of specific vocalizations, or both rate and type of vocalization. Finally, whereas we were unable to replicate the study with a different focal male and focal female respectively, we did replicate their responses to the release of male and female seals into the focal animal's territory as well as record the behaviors ensuing from the addition of three free-ranging female seals.

In conclusion we acknowledge the limitations of this single subject study. However we believe that the uniqueness of the research design, the opportunity to systematically insert male and female Weddell seals into a male's territory, the relative consistency of the reactions the focal male and female made to the introduction of captured and free-ranging seals, and the ability to record the vocalizations and non-vocal behaviors from known individuals interacting around an ice hole all together made a solid contribution to the literature concerning the ways in which male and female Weddell seals use vocalizations during the breeding season to enhance their reproductive success.

\section{Acknowledgements}

The research discussed in this paper was funded by Grant B002 from the National Science Foundation. Financial support for the first author was provided through research and teaching assistantships from the Departments of Marine Biology and Wildlife and Fisheries Sciences, and the Offices of Graduate Studies of Texas A\&M University in College Station and in Galveston. The second author was funded partially through the Brown Foundation, Houston, TX. We thank Michael Castellini, Lee Fuiman, Markus Horning, Shane Kanatous, and Terrie Williams, for their assistance in data collection. We also thank Lisa Campbell and Bernd Würsig for reviewing this manuscript.

Much of the data reported here was used by the first author in partial fulfilment of her Master's thesis. These data have not been published elsewhere. All experimental procedures followed the guidelines of the NIH and were evaluated and approved by the members of the institutional animal care and use committees at Texas A \& M University at Galveston, University of Texas at Austin, and the University of California at Santa Cruz.

\section{References}

Aberson, C. L. (2010). Applied power analysis for the behavioral sciences. New York: Routledge Taylor \& Francis Group.

Boness, D. J. (1991). Determinants of mating systems in the Otariidae (Pinnipedia). In D. Renouf (Ed.), The behavior of pinnipeds (pp. 1-44). Cambridge MA: Chapman and Hall.

Boness, D. J., Bowen, W. D., \& Francis, J. M. (1993). Implications of DNA fingerprinting for understanding pinniped mating systems and reproductive strategies. In I. L. Boyd (Ed.), Marine mammals: Advances in behavioral and population biology (pp. 61-94). London, UK: Zoological Society of London.

Bradbury, J. W., \& Vehrencamp, S. L. (1998). Signal evolution. In J. W. Bradbury (Ed.), Principles of animal communication (pp. 497-536). Sunderland, MA: Sinauer Associates.

Brown, L., \& Downhower, J. F. (1988). Analyses in behavioral ecology: A manual for lab and field. Sunderland, MA: Sinauer Associates.

Cheney, D. L., \& Seyfarth, R. M. (1980). Vocal recognition in free-ranging vervet monkeys. Animal Behaviour, 28, 362-367.

Cohen, J. (1960). A coefficient of agreement for nominal scales. Educational Psychological Measurement, 20, 3746.

Cohen, J. (1988). Statistical power analysis for the behavioral sciences, $2^{\text {nd }}$ ed. Hillsdale, NJ: Erlbaum.

Collins, K. T., \& Terhune, J. M. (2006). Geographic variation of Weddell seal (Leptonychotes weddellii) airborne 
mother-pup vocalizations. Polar Biology, 30, 1373-1380.

Curran-Everett, D. (2000). Multiple comparisons: Philosophies and illustrations. American Journal Physiology: Regulatory Integrative Comparative Physiology, 279, R1-R8.

Davis, R. W., Fuiman, L. A., Williams, T. M., Horning, M., \& Hagey, W. (2003). Classification of Weddell seal dives based on three-dimensional movements and video-recorded observations. Marine Ecology Progress Series, 264, 109-122.

Dudzinski, K. M., Thomas, J. A., \& Douaze, E. (2002). Communication. In W. E. Perrin, B. Wursig, \& J. G. M. Thewissen (Eds.), Encyclopedia of marine mammals (pp. 248-268). San Diego, CA: Academic Press.

Emlen, S. T. \& Oring, L. W. (1977). Ecology, sexual selection, and evolution of mating systems. Science, 197, 215223.

Freeman, S. \& Herron, J. C. (2001). Sexual selection. In S. Freeman (Ed.), Evolutionary analysis (pp. 289-330). Upper Saddle River, NJ: Prentice-Hall.

Green, K., \& Burton, H. R. (1988). Annual and diurnal variations in the underwater vocalizations of Weddell seals. Polar Biology, 8, 161-164.

Harcourt, R. G., Kingston, J. J., Cameron, M. F., Waas, J. R., \& Hindell, M. A. (2007). Paternity analysis shows experience, not age, enhances mating success in an aquatically mating pinniped, the Weddell seal (Leptonychotes weddellii). Behavioral Ecology \& Sociobiology, 61, 643-652.

Harrington, F. H. (1979). Wolf howling and its role in territory maintenance. Behaviour, 68, 207-249.

Harrington, F. H. (1987). Aggressive howling in wolves. Animal Behaviour, 3, 7-12.

Hollis, K. L., Cadieux, E. L., \& Colbert, M. M. (1989). The biological function of Pavlovian conditioning: (Trichogaster trichopterus). Journal of Comparative Psychology, 103, 115-121.

Hollis, K. L., Phar, V. L., Dumas, M. J., Britton, G. B., \& Field, J. (1997). Classical conditioning provides paternity advantage for territorial male blue gouramis (Trichogaster trichopterus). Journal of Comparative Psychology, 111, 219-225.

Kaufman, A. B., \& Rosenthal, R. (2009). Can you believe my eyes? The importance of interobserver reliability statistics in observations of animal behaviour. Animal Behaviour, 78, 1487-1491.

Kooyman, G. L. (1981). Weddell seal: Consummate diver. New York: Cambridge University Press.

Krein, T., \& Clark, C. (2011). Raven Pro: Bioacoustics Research Program. Interactive Sound Analysis Software (Version 1.4). [Computer software]. Ithaca, NY: The Cornell Lab of Ornithology. Available from http://www.birds.cornell.edu/raven.

Le Boeuf, B. J. (1991). Pinniped mating systems on land, ice and in the water: Emphasis on the Phocidae. In D. Renouf (Ed.), Behaviours of pinnipeds (pp. 45-65). Cambridge, UK: Chapman and Hall.

Mhartre, N., \& Balakrishnan, S. (2006). Male spacing behavior and acoustic interactions in a field cricket: Implications for female mate choice. Animal Behaviour, 72, 1045-1058.

Moors, H. B., \& Terhune, J. M. (2004). Repetition patterns in Weddell seal (Leptonychotes weddellii) underwater multiple element calls. Journal of the Acoustical Society of America, 116, 1261-1270.

Oetelaar, M. L., Terhune, J. M., \& Burton, H. R. (2003). Can the sex of a Weddell seal (Leptonychotes weddellii) be identified by its surface call? Aquatic Mammals, 29, 261-267.

Owings, D. H., \& Coss, R. G. (1977). Snake mobbing by California ground squirrels: Adaptive variation and ontogeny. Behaviour, 62, 50-69

Owings, D. H., \& Morton, E.S. (1998). Animal vocal communication: A new approach. New York: Cambridge University Press.

Pahl, P. C. (1995). The repertoire and geographic variation of the underwater vocalizations of the Weddell seal, Leptonychotes weddellii, at the Vestfold Hills, Antarctica. (Unpublished master's thesis), University of New Brunswick, Saint John, Canada.

Pahl, P. C., Terhune, J. M., \& Burton, H. R. (1996). Proportional weekly use of underwater call types by Weddell seals, Leptonychotes weddellii (Pinnipedia: Phocidae), during the breeding season at the Vestfold hills. Australian Journal of Zoology, 44, 75-79.

Pahl, P. C., Terhune, J. M., \& Burton, H. R. (1997). Repertoire and geographic variation in underwater vocalizations of Weddell seals (Leptonychotes weddellii, Pinnipedia: Phocidae) at the Vestfold Hills, Antarctica. Australian Journal of Zoology, 45, 171-187.

Peek, F. (1972). An experimental study of the territorial function of vocal and visual display in the male redwing blackbird. Animal Behaviour, 20, 112-118.

Ray, C., \& Schevill, W. E. (1967). Noisy underwater world of the Weddell seal. Animals, 10, 109-113.

Rogers, T. L. (2003). Factors influencing the acoustic behavior of male phocid seals. Aquatic Mammals, 29, 247- 
260.

Rogers, L. J., \& Kaplan, G. (2002). Songs, roars, and rituals. Cambridge, MA: Harvard University Press.

Rouget, P. A., Terhune, J. M., \& Burton, H. R. (2007). Weddell seal underwater calling rates during the winter and spring near Mawson Station, Antarctica. Marine Mammal Science, 23, 508-523.

Seyfarth, R. M., \& Cheney, D. L. (1986). Vocal development in vervet monkeys. Animal Behaviour, 34, $1640-1658$.

Stirling, I., Calvert, W., \& Spencer, C. (1987). Evidence of stereotyped underwater vocalizations of male Atlantic walruses (Odobenus rosmarus rosmarus). Canadian Journal of Zoology, 65, 2311-2321.

Struhsaker, T. T. (1967). Auditory communication among vervet monkeys (Cercopithecus aethiops) In S. A. Altmann (Ed.). Social communication among primates (pp. 281-324). Chicago: University of Chicago Press.

Terhune, J. M., Burton, H. R., \& Green, K. (1994). Weddell seal in-air call sequences made with closed mouths. Polar Biology, 14, 117-122.

Terhune, J. M., Grandmaitre, N. C., Burton, H. R., \& Green, K. (1994). Weddell seals lengthen many underwater calls in response to conspecific vocalizations. Bioacoustics, 5, 223-226.

Thomas, J. A. (1991). The sounds of seal society. Natural History, 3, 46-55.

Thomas, J. A., Ferm, L. M., \& Kuechle, V. B. (1987). Silence as an anti-predation strategy by Weddell seals. Antarctic Journal, 22, 232-234.

Thomas, J. A., Ferm, L. M., \& Kuechle, V. B. (1988). Patterns of underwater calls from Weddell seals (Leptonychotes weddellii) during the breeding season at McMurdo Sound, Antarctica. Antarctic Journal, $23,146-148$.

Thomas, J. A., \& Kuechle, V. B. (1982). Quantitative analysis of Weddell seal (Leptonychotes weddellii) underwater vocalizations at McMurdo Sound, Antarctica. Journal of the Acoustical Society of America, 72, 1730-1738.

Thomas, J. A., Puddicombe, R. A., George, M., \& Lewis, D. (1988). Variations in underwater vocalizations of Weddell seals (Leptonychotes weddellii) at the Vestfold Hills as a measure of breeding population discreteness. Hydrobiologica, 165, 279-284.

Thomas, J. A., \& Stirling, I. (1983). Geographic variation in the underwater vocalizations of Weddell seals (Leptonychotes weddellii) from Palmer Peninsula and McMurdo Sound, Antarctica. Canadian Journal of Zoology, 61, 2203-2212.

Thomas, J. A., Zinnel, K. C., \& Ferm, L. M. (1983). Analysis of Weddell seal (Leptonychotes weddellii) vocalizations using underwater playbacks. Canadian Journal of Zoology, 61, 1448-1456.

Tripovich, J. S., Rogers, T. L., \& Arnould, J. P. Y. (2005). Species-specific characteristics and individual variation of the bark call produced by male Australian fur seals, Arctocephalus pusillus doriferus. The International Journal of Animal Sound and its Recording, 15, 79-96.

Trivers, R. L. (1972) Parental investment and sexual selection. In B. Campbell (Ed.), Sexual selection and the descent of man, 1871-1971 (pp 136-179). Chicago: Aldine Publishing Company

Turnbull, S. D., \& Terhune, J. M. (1993). Repetition enhances hearing detection thresholds in a harbour seal (Phoca vitulina). Canadian Journal of Zoology, 71, 926-932.

Van Parijs, S. M., Lydersen, C., \& Kovacs, K. M. (2003). Vocalizations \& movements suggest alternative mating tactics in male bearded seals. Animal Behaviour, 65, 273-283.

Van Parijs, S. M., Lydersen, C., \& Kovacs, K. M. (2004). Effects of ice cover on the behavioral patterns of aquaticmating male bearded seals. Animal Behaviour, 68, 89-96.

Wartzok, D., \& Ketten, D. R. (1999). Marine mammal sensory systems. In J. E. Reynolds, III \& S. A. Rommel (Eds.), Biology of marine mammals (pp. 117-175). Washington, D.C.: Smithsonian Institution Press.

Watkins, W. A., \& Schevill, W. E. (1968). Underwater playback of their own sounds to Leptonychotes (Weddell seals). Journal of Mammalogy, 49, 287-296.

Watkins, W. A., \& Schevill, W. E. (1979). Distinctive characteristics of underwater calls of the harp seal (Phoca groenlandica) during the breeding season. Journal of the Acoustical Society of America, 66, 983-988.

Williams, T. M. (2003). Sunbathing seals of Antarctica. Natural History, 112, 50-55.

Wilson, E. (1907). On the whales, seals, and birds of the Ross Sea and South Victoria Land. In R. R. Scott (Ed.), The voyage of the Discovery 2 (pp. 269-294). London: Smith, Elder and Co. 